\title{
Properties of feedback mechanisms on digital platforms: an exploratory study
}

\author{
Andreas J. Steur ${ }^{1} \mathbb{D} \cdot$ Mischa Seiter $^{1} \mathbb{D}$
}

Published online: 27 November 2020

(C) The Author(s) 2020

\begin{abstract}
Many digital platforms implement feedback mechanisms as a means to control the behavior of their users. However, there is a lack of theoretical explanation regarding the interrelation between design characteristics of feedback mechanisms and their effects. In this study, we interpret feedback mechanisms as a specific type of management control to propose properties as a new theoretical perspective on this problem. Our exploratory study has two objectives. First, we analyze how digital platforms design their feedback mechanisms. Second, we examine to what extent feedback mechanisms comply with standards given in the management control literature for our newly introduced properties. Analyzing the 102 most widely used platforms in Germany, we find dominant patterns in nearly all design characteristics (e.g., query method, submission category and scale level). Furthermore, we find mixed compliance of feedback mechanisms with our introduced properties (e.g., low precision but high sensitivity and verifiability). For a deeper understanding of these results, especially the reasons for the design choices, we conduct 14 semi-structured expert interviews. We find simplicity and inspiration from other platforms to be dominant drivers for design choices.
\end{abstract}

Keywords Feedback mechanism $\cdot$ Design characteristics $\cdot$ Properties $\cdot$ Digital platform $\cdot$ Management control

JEL classification L14 · M10

Andreas J. Steur

andreas.steur@uni-ulm.de

Mischa Seiter

mischa.seiter@uni-ulm.de

1 Ulm University, Helmholtzstraße 22, Ulm, Germany 


\section{Introduction}

In recent years, there has been growing interest in digital platforms in research as well as in practice. Driven by the fact that some of the highest-valued companies (e.g., Apple and Amazon), have implemented successful platforms, many others have been following these examples (Evans and Schmalensee 2016; Parker et al. 2016). Digital platforms such as marketplaces, social media platforms, and Internet-of-Things platforms represent "a new business model that uses technology to connect people, organisations, and resources in an interactive ecosystem in which amazing amounts of value can be created and exchanged" (Parker et al. 2016).

An example of such a platform is eBay, which matches sellers of products and buyers via its marketplace. The buyers and sellers are also called market sides (Cabral and Hortaçsu 2010; Melnik and Alm 2002). The sellers can present their products and additional information about them (e.g., price and condition) and can also upload photos. Customers can buy products either in the form of an auction or at a fixed price (Cabral and Hortaçsu 2010). After the transaction, both the buyer and the seller can provide feedback. As is usual in the context of platforms, we consider users to be both buyers and sellers.

The products offered by the sellers, often referred to as external resources, are crucial to the platform because, without them, there would not be any transaction (van Alstyne et al. 2016). The sellers and buyers often do not know each other before the transaction, which results in information asymmetries. After an agreement between the buyer and the seller, the buyer can pay or not. However, whether and when the buyer will pay is unclear to the seller. The seller can avoid negative consequences from this information asymmetry by waiting for the payment before shipping. In addition, the buyer also has an information deficit, as the buyer does not know whether he or she will receive the product and whether its quality will be as described. However, buyers cannot solve the problems resulting from information asymmetries. The resulting decrease in external resource quality and possible negative behavior can lead to users losing confidence in the platform (Bolton et al. 2013) and consequently ceasing to use it.

In practice, there are several control mechanisms for this problem, such as gatekeeping, recommender systems (Tiwana 2014), and feedback mechanisms (Bolton et al. 2013). In this paper, we focus on feedback mechanisms because they represent the best-known application (Dellarocas 2003) and a widely established mechanism (Gutt et al. 2019). For instance, eBay uses a feedback mechanism that many studies have analyzed (e.g., Bolton et al. 2013; Dellarocas et al. 2004). Within this feedback mechanism, both sellers and buyers can evaluate each other after a successful transaction (Bolton et al. 2013). In particular, they can specify whether the transaction was positive, neutral or negative (Kornberger et al. 2017). Further, buyers can give an additional detailed seller rating (Bolton et al. 2013; Kornberger et al. 2017) and rate several categories such as whether the item was as described, communication, shipping time and shipping charges. The sensitivity relates among the design characteristics reciprocity and scale level (Kornberger et al. 2017). 
The positive effects of well-designed feedback mechanisms have been shown in many studies; for example, the effects on revenue are well-known (e.g., Ba and Pavlou 2002; Bajari and Hortaçsu 2003; Dellarocas et al. 2004; McDonald and Slawson 2002; Melnik and Alm 2002; Resnick et al. 2006; Resnick and Zeckhauser 2002). However, these feedback mechanisms cause several dysfunctional effects. For example, almost all feedback on eBay's marketplace is positive (Dellarocas and Wood 2008; Resnick and Zeckhauser 2002). This frequent positive feedback is not necessarily related to good transactions and user behavior. Indeed, users may take "revenge" for negative feedback; thus, for example, a buyer may give a seller positive feedback even on an unsatisfactory transaction to ensure that the buyer's reputation is not damaged by retaliatory negative feedback from the seller (Bolton et al. 2013). Moreover, such dysfunctional effects extend beyond the mechanism of eBay. For instance, manipulations such as inconsistent feedback occur within other feedback mechanisms (e.g., Amazon, TripAdvisor and Booking.com) (Fazzolari et al. 2017; Mayzlin et al. 2014; Mudambi et al. 2014). These dysfunctional feedback mechanisms may lead to a decline in users' motivation to provide feedback (McDonald and Slawson 2002) and, as a result, may cause a negative attitude towards feedback (Abramova et al. 2016).

Although it seems obvious that dysfunctional effects of feedback mechanisms can be seen as a consequence of their design, there is a lack of theoretical explanation of this interrelation. In this study, we draw on the management control literature to overcome this gap. Management control systems exist in multiple forms, in which a manager tries to align a subordinate's performance with the business objectives (Anthony et al. 2014). Control mechanisms are implemented to influence the behavior of subordinates to achieve the organization's objectives (Merchant and van der Stede 2017). We interpret feedback mechanisms as a specific type of control mechanism that is implemented as a means to influence users to implement the platform provider's strategy (e.g., to improve transaction quality). The literature on management control has established several standards to avoid dysfunctional effects that can be used as a theoretical basis in this study. Therefore, we propose the following research questions:

(1) How do digital platforms design their feedback mechanisms?

(2) To what extent do digital platforms' feedback mechanisms comply with the standards given in the literature on management control systems properties?

To answer our first research questions, we introduce a morphological box of design characteristics obtained during a literature analysis, as well as theoretical considerations. Based on the morphological box, we conduct a descriptive analysis of various feedback mechanisms and their design characteristics.

Furthermore, we adapt properties that are discussed in management control literature as necessary to design management control systems. These properties form the basis of the subsequent analysis of whether the feedback mechanisms of the digital platforms comply with the standards given in the literature on the management control systems properties. 
Based on the results of the descriptive analysis, we interview experts to gain insight into the specific feedback mechanism and to unravel reasons for different design choices and the compliance with the standards given in the literature on management control systems properties.

Through our research, we contribute to the development and structure of the research field of feedback mechanisms. We show how digital platforms design their feedback mechanisms and provide insight into their decisions. In particular, our paper offers a morphological box of those design characteristics and provides a framework for operators to design, implement, or redesign feedback mechanisms. Furthermore, our analysis shows to what extent existing feedback mechanisms comply with the properties of management control systems. Moreover, it reveals reasons for compliance based on expert interviews and highlights trade-offs in designing feedback mechanisms.

The remainder of this paper is organized as follows: Based on the design characteristics of feedback mechanisms and the standards given in the management control literature, we develop a framework for designing feedback mechanisms in Sect. 2. Section 3 presents the methods we use to analyze existing feedback mechanisms with regard to their compliance with the framework's properties and the method of the qualitative approach. Our results are presented in Sect. 4. We discuss results and paths for future research in Sect. 5. Section 6 summarizes and concludes.

\section{Literature review and theoretical framework}

\subsection{Design characteristics of feedback mechanisms on digital platforms}

Feedback mechanism research is diverse and includes, among others management control systems, behavioral economics, digital platforms, and information systems research. The corresponding literature covers many terms to describe feedback mechanisms. In addition to "feedback mechanisms" (e.g., Ba and Pavlou 2002; Chen et al. 2017; Dellarocas 2003; Dellarocas and Wood 2008) the literature refers to the terms "evaluating infrastructure" (e.g., Kornberger et al. 2017), "feedback systems" (e.g., Bolton et al. 2013, 2018), "ratings" (e.g., Abramova et al. 2016), "online reviews" (e.g., Gutt et al. 2019; Mayzlin et al. 2014), and "reputation systems" (e.g., Bharadwaj and Al-Shamri 2009; Resnick and Zeckhauser 2002). Due to the diversity of research, there is no standard definition of feedback mechanisms. Similar to Kornberger et al. (2017), we consider feedback mechanisms to be a type of formal control mechanism.

Feedback mechanisms should ensure proper transaction quality, in terms of both the behavior of users and the conditions of external resources. Feedback helps users to receive information about the conditions of previous transactions, such as product or service quality, and about potential opportunistic behavior of users (Nosko and Tadelis 2015). Therefore, feedback mechanisms aim to reduce information asymmetries between users (McDonald and Slawson 2002), increase trust between users (Ba and Pavlou 2002), and avoid the problem of adverse selection and moral hazard (Hui et al. 2019). Furthermore, feedback mechanisms enable users to be ranked 
and compared. Therefore, users facing a transaction decision can decide more quickly, resulting in decreased search and transaction costs (Chen et al. 2017; Hagiu 2009; Zhang et al. 2016; Zhang and Sarvary 2015).

In summary, feedback mechanisms have information and incentive functions. Feedback mechanisms as a formal control mechanism must be distinguished from word-of-mouth because these mechanisms have an unpredictable scale and low costs. The lower costs of feedback mechanisms compared to word-of-mouth are related to platform users' reciprocal evaluation and the resulting control and monitoring of the users' performance by automatic feedback mediators (Dellarocas 2003).

Feedback mechanisms are designed in various forms. To get a better understanding of feedback mechanisms, we describe different design characteristics of feedback mechanisms using a morphological box. The morphological box is based on several specifications obtained during the literature analysis and theoretical considerations. We separate criteria that primarily contribute to the provision of feedback from criteria that influence users in consuming feedback for their transaction decisions.

Table 1 shows various design characteristics of feedback mechanisms and their possible specifications. The design characteristics of feedback mechanisms include reciprocity, submission restriction, query method, submission categories, scale level, feedback evaluation, filter, sorting, symbol, and color. In detail, we describe the design characteristics of feedback mechanisms.

Feedback mechanisms differ with regard to their reciprocity. The submission may concern only the users of one market side (one-sided) or the users of two or more market sides (multi-sided) (Bolton et al. 2004). Platforms use one-sided feedback to evaluate users of different market sides (Chua and Banerjee 2015; Einav et al. 2015; Tadelis 2016). For example, within Amazon's marketplace, customers evaluate sellers' performance. However, an evaluation of the buyer is not possible. In contrast to one-sided feedback, reciprocal feedback is related to a mutual rating of different market sides (Bolton et al. 2013). For instance, Airbnb provides reciprocal feedback in which guests evaluate the hosts' service and vice versa.

Another characteristic that refers to users providing feedback is that of submission restriction. That is, the operator can restrict users from giving feedback. In some cases, there may be no restrictions, so that all users can give feedback regardless of whether or not they interacted, while in other cases users may be permitted to provide feedback only after a transaction. Moreover, this feedback may be voluntarily or required.

Another characteristic, the query method, refers to the type of feedback that is requested. This query can be qualitative, quantitative, or both. Qualitative feedback includes textual information, while quantitative feedback is given using a predefined scale level (Chevalier and Mayzlin 2006; Mudambi et al. 2014).

Closely linked to the query method is the characteristic of submission categories. Users can give feedback for the entire transaction (overall rating) or for two or more categories. While the overall rating is easy to provide feedback, which in turn reduces rating costs for users, the use of several categories provides more accurate information for the rated users as well as other users who are deciding about a possible transaction. However, this information is limited to the defined categories. 
Specific evaluation categories could still be weighted according to the platform's objectives. However, it should be guaranteed that the users providing feedback, as well as users who are facing an interaction decision on the platform, understand the evaluation categories of the platform. Furthermore, the overall rating can be weighted according to price, rating skills, and timing (Panagopoulos et al. 2017). Based upon individual quantitative feedback, platform operators can display several measures according to the reputation of each user. For example, the number of previous ratings of each scale level or the percentage of positive feedback of total provided feedback could be displayed (Nosko and Tadelis 2015).

Table 1 Morphological box of feedback mechanisms

\begin{tabular}{|c|c|c|c|c|c|c|c|c|c|c|}
\hline & $\begin{array}{l}\text { Design } \\
\text { characteristics }\end{array}$ & Description & \multicolumn{8}{|c|}{ Specification } \\
\hline \multirow{5}{*}{ 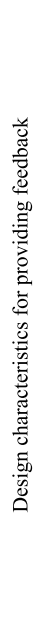 } & Reciprocity & $\begin{array}{l}\text { number of } \\
\text { market } \\
\text { sides } \\
\text { providing } \\
\text { feedback }\end{array}$ & \multicolumn{4}{|c|}{ one-sided } & \multicolumn{4}{|c|}{ multi-sided } \\
\hline & $\begin{array}{l}\text { Submission } \\
\text { restriction }\end{array}$ & $\begin{array}{l}\text { restriction } \\
\text { of the users } \\
\text { providing } \\
\text { feedback }\end{array}$ & \multicolumn{3}{|c|}{ none } & \multicolumn{3}{|c|}{$\begin{array}{l}\text { voluntarily after } \\
\text { transaction }\end{array}$} & \multicolumn{2}{|c|}{ required after transaction } \\
\hline & Query method & $\begin{array}{l}\text { type of } \\
\text { feedback } \\
\text { request }\end{array}$ & \multicolumn{3}{|c|}{ qualitative } & \multicolumn{3}{|c|}{ quantitative } & \multicolumn{2}{|c|}{ both } \\
\hline & $\begin{array}{l}\text { Submission } \\
\text { category }\end{array}$ & $\begin{array}{l}\text { number of } \\
\text { queried } \\
\text { categories } \\
\text { within the } \\
\text { feedback } \\
\text { submission }\end{array}$ & \multicolumn{3}{|c|}{ overall rating } & \multicolumn{2}{|c|}{ two categories } & \multicolumn{3}{|c|}{$\cdots$} \\
\hline & Scale level & $\begin{array}{l}\text { scale level } \\
\text { used within } \\
\text { the } \\
\text { feedback }\end{array}$ & none $^{\mathrm{a}}$ & 1 & \multicolumn{3}{|c|}{2} & & 5 & $\cdots$ \\
\hline \multirow{5}{*}{ 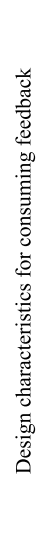 } & $\begin{array}{l}\text { Feedback } \\
\text { evaluation }\end{array}$ & $\begin{array}{l}\text { possibility } \\
\text { to evaluate } \\
\text { existing } \\
\text { feedback }\end{array}$ & \multicolumn{4}{|c|}{ not possible } & \multicolumn{4}{|c|}{ possible } \\
\hline & Filter & $\begin{array}{l}\text { restriction } \\
\text { type of } \\
\text { feedback } \\
\text { display }\end{array}$ & none & $\begin{array}{l}\text { key- } \\
\text { words }\end{array}$ & rating & $\begin{array}{c}\text { sub- } \\
\text { mission }\end{array}$ & $\begin{array}{l}\text { user } \\
\text { type }\end{array}$ & $\begin{array}{l}\text { trans- } \\
\text { action } \\
\text { type }\end{array}$ & $\ldots$ & $\begin{array}{l}\text { mul- } \\
\text { tiple }\end{array}$ \\
\hline & Sorting & $\begin{array}{l}\text { sorting type } \\
\text { of existing } \\
\text { feedback }\end{array}$ & none & date & rating & $\begin{array}{l}\text { use- } \\
\text { fulness }\end{array}$ & $\begin{array}{l}\text { rele- } \\
\text { vance }\end{array}$ & $\begin{array}{l}\text { user } \\
\text { type }\end{array}$ & $\cdots$ & $\begin{array}{l}\text { mul- } \\
\text { tiple }\end{array}$ \\
\hline & Symbol & $\begin{array}{l}\text { symbols } \\
\text { used within } \\
\text { the } \\
\text { feedback }\end{array}$ & none $^{a}$ & stars & & nbs & & & & \\
\hline & Color & $\begin{array}{l}\text { colors used } \\
\text { within the } \\
\text { feedback }\end{array}$ & none $^{\mathrm{a}}$ & yellow & & d & & & & \\
\hline
\end{tabular}

${ }^{a}$ Within this specification, there is only qualitative feedback. Therefore, no predefined scale, no symbol or different colors are used to represent the feedback. 
The platform can use different scales (e.g., five-point scale) for the evaluation (Jiang and Guo 2015; Sparling and Sen 2011). However, selecting an incorrect scale may cause dysfunctional effects. For example, a feedback scale consisting of only one positive and one negative option may discourage a user from providing any feedback if the user perceives the transaction as neutral. This kind of measurement may cause extreme values. The advantages of quantitative feedback are the straightforward measurement and the possibility of aggregating the individual ratings to an overall rating per user.

Feedback evaluation is another criterion that enables users consuming feedback to react to and evaluate existing feedback (Mudambi and Schuff 2010). This evaluation is based on the same characteristics described for the feedback mechanisms. For example, this evaluation can contain several categories (e.g., usefulness) and can be qualitative or quantitative.

In addition to the evaluation of existing feedback, there are differences in the display of feedback (Gutt et al. 2019). For instance, platforms can implement a filter to limit the display of current feedback according to defined categories, such as keywords within qualitative feedback. Furthermore, there are filters for different rating levels, submission categories, user types, transaction types, or others. Platforms can also use multiple filters. In addition to filters, operators can also offer feedback sorting according to date, rating level, usefulness, relevance, or user type. Multiple sorting is also possible.

There are further criteria that can also be considered when designing these mechanisms. Operators can use different symbols and colors within the feedback mechanism (Berger and Schmitt 2005). For instance, some platforms use thumbs, smiles, stars, or sliders as symbols (Sparling and Sen 2011). Moreover, operators use different colors (e.g., yellow, red, blue) to display the rating or vary the colors within the scale. The specification of the evaluation can be highlighted using different colors (Kornberger et al. 2017; Sänger and Pernul 2018).

In the literature, several publications have provided an overview of the feedback mechanism characteristics (e.g., Gutt et al. 2019). However, different design approaches affect the willingness to provide feedback in different ways. For instance, a platform should only use multi-sided feedback if the provision of multi-sided feedback is simultaneous or blind. In other cases, contributors within multi-sided mechanisms often wait to give their ratings in order to potentially take revenge for negative feedback. This dysfunctional effect results in higher scores and less negative feedback (Bolton et al. 2013). Another type of feedback mechanism that sets an incentive to provide negative feedback is the withdrawal option. This option offers the opportunity for compensation and allows both users to withdraw the feedback later. Consequently, this option can be used to turn an unhappy user into a happier one, thereby increasing trust (Bolton et al. 2018).

Another characteristic affecting the provision of feedback is the query method (e.g., qualitative and quantitative feedback). Qualitative feedback has many benefits. For example, it can enable users to give more open and detailed feedback, providing more informative evaluations of users, which can also help users who are about to make an interaction decision. However, the information content of feedback differs (Mudambi et al. 2014). Therefore, in practice, further mechanisms have been 
developed to make it possible to identify relevant information among individual pieces of feedback more quickly (Liu and Park 2015; Mudambi and Schuff 2010; Schindler and Bickart 2012). A precise evaluation is possible using various categories. However, these predefined categories cannot include all topics that are relevant for users. Thus, quantitative components are easier to handle than multiple categories.

The consumption of feedback and the related transaction decisions of users can also be affected by different design approaches. For instance, both filter and sorting options allow users to change the way existing feedback is displayed so that they can quickly find the feedback they need in order to make an interaction decision. Therefore, filter and sorting options contribute to the reduction of search costs. Moreover, different symbols and colors within feedback may influence the perception of the feedback for users as to whether the feedback is positive or not. Symbols may also affect the provision of feedback. Nevertheless, platforms use symbols, colors, and scales only to display quantitative feedback.

In addition to the characteristics that influence the provision of feedback, outcomes also influence the function of a feedback mechanism. In this stream of research, it is well known that feedback mechanisms have a positive influence on trust in the market or on the platform and thus on the price and transaction volume (e.g., Ba and Pavlou 2002; Bajari and Hortaçsu 2003; Bolton et al. 2004; Dellarocas et al. 2004; McDonald and Slawson 2002; Melnik and Alm 2002; Resnick et al. 2006; Resnick and Zeckhauser 2002). Although there is a free-rider problem, most users provide feedback; however, most of it is positive (Hu et al. 2017; Resnick and Zeckhauser 2002; Zervas et al. 2015). Furthermore, users weight negative feedback more strongly than positive feedback and weight recent feedback more strongly than older feedback (Bolton et al. 2004). Possible reasons for this dysfunctional effect include incorrectly designed feedback mechanisms, such as reciprocal mechanisms in which users take revenge for negative feedback (Bolton et al. 2013). In addition to the behavioral economic aspects, there is further literature on various forms of manipulation, their detection, and their design to prevent manipulation (e.g., Hoffman et al. 2009; Jøsang et al. 2007; Mayzlin et al. 2014; Sänger and Pernul 2018). Platform operators should seek to avoid manipulations, such as ballot stuffing, badmouthing and Sybil attacks (Hoffman et al. 2009).

\subsection{Management control systems}

Management control systems aim to implement business strategy (Anthony et al. 2014; Merchant and van der Stede 2017). Management control is thus "the systematic process by which the organization's higher-level managers influence the organization's lower-level managers to implement the organization's strategies" (Anthony et al. 2014). This separation of high-level and lower-level managers is crucial with regard to the decentralized organization of companies. However, a decentralized or lower-level manager does not always act in line with organizational goals. This divergence results from lower-level managers not entirely understanding, not agreeing with, or not having the resources to achieve the goals or strategies of the 
higher level (Anthony et al. 2014). Therefore, management control systems help to uncover whether lower-level managers behave in accordance with organizational strategy (Merchant and van der Stede 2017; Simons 1995). Moreover, management control systems "provide information that is intended to be useful to managers in performing their jobs and assisting organizations in developing and maintaining viable patterns of behavior" (Otley 1999). In the literature, various terms are used for high-level and low-level managers of a company (e.g., senior management and decentralized manager) (Anthony et al. 2014). In this paper, we use the terms "managers" for high-level managers and "subordinates" for lower-level managers.

Management control systems exist in many different forms, in which the manager tries to align the subordinate's performance with the business objectives (Anthony et al. 2014). For example, control mechanisms can be divided into formal and informal control mechanisms (Chenhall 2003; Ferreira and Otley 2009; Langfield-Smith 1997), both of which influence the behavior of subordinates to achieve the organization's objectives (Merchant and van der Stede 2017). Formal control mechanisms comprise specific rules and standard procedures for organizations and allow a manager to control the organization's objectives (Langfield-Smith 1997). Informal control mechanisms are not explicitly designed. They contain the organization's unwritten rules and often derive from the organization's culture (Langfield-Smith 1997). Altogether, management control systems include strategic planning, budgeting, resource allocation, performance measurement, and pricing (Merchant and van der Stede 2017).

However, management control systems are not flawless, and dysfunctional effects can occur when the wrong design is used. An appropriate design is essential, because management control systems are directly related to organizational commitment and trust in managers (Magner et al. 2006). Furthermore, perceived fairness influences the behavior of a subordinate (Klein et al. 2019; Langevin and Mendoza 2013; Little et al. 2002) and leads to less budgetary slack, higher job performance, and greater helping behavior (Magner et al. 2006). Conversely, dysfunction results in unethical behavior (Langevin and Mendoza 2013; Merchant and van der Stede 2017), which mainly consists of budgetary slack (e.g., Dunk 1993; Libby 2003; Merchant 1985) and data manipulation (e.g., DeFond and Park 1997; Merchant and Rockness 1994; Merchant and van der Stede 2017).

The negative attitudes and behavior result from subordinates' perception of injustice (Langevin and Mendoza 2013). Such injustice includes a lack of fairness in the distribution of resources and procedural components, such as the distribution of rewards and evaluations, and a lack of appropriate treatment of subordinates, such as efforts to foster respect and dignity (Alexander and Ruderman 1987; Folger and Konovsky 1989; Langevin and Mendoza 2013; Lindquist 1995; Roberson and Stewart 2006).

Langevin and Mendoza (2013) developed a framework to avoid perceived injustice and, thus, negative attitudes and behavior among subordinates. This framework includes the properties of participation in target-setting, the controllability principle, the use of multiple performance measures, and feedback quality. These properties form the basis for the later development of the theoretical framework for analyzing 
Table 2 Management control system properties

\begin{tabular}{ll}
\hline Property & Explanation \\
\hline Precision & $\begin{array}{c}\text { The management control system does not include uncontrollable fac- } \\
\text { tors for the subordinate that cause distortion (Burkert et al. 2011). } \\
\text { The management control system covers changes caused by the subordi- } \\
\text { nate's level of effort (Banker and Datar 1989; Burkert et al. 2011). } \\
\text { The subordinate understands the management control system and } \\
\text { knows how it is calculated (Merchant 2006). } \\
\text { Verifiability } \\
\text { The management control system includes multiple measures (e.g., both } \\
\text { financial and non-financial measures) (Burney et al. 2009; Ittner et al. } \\
\text { 2003; Kaplan and Norton 1996). } \\
\text { The subordinate is involved in the target-setting process and is given } \\
\text { specific control over the outcome (Brownell 1982; Langevin and } \\
\text { Mendoza 2013; Milani 1975). } \\
\text { The manager should respond to the subordinates on their measured } \\
\text { performance (Langevin and Mendoza 2013). The response should be } \\
\text { clear, timely and accurate (Magner et al. 2006). }\end{array}$ \\
\hline
\end{tabular}

properties of feedback mechanisms on digital platforms. We will examine the properties of the framework (see Table 2) in more detail.

A property of the framework of Langevin and Mendoza (2013) is controllability, which implies that the measured indicator should be within the subordinate's control or influence (Holmström 1979; Merchant 2006). Performance measures that are not influenceable are related to lower motivation and therefore cause dysfunctional behavior as well as lower performance of the subordinate (Dent 1987; Giraud et al. 2008; Huffman and Cain 2000; McNally 1980; Merchant 2006; Simons 1995). However, the controllability of measures is not observable and is based on the properties of precision and sensitivity (Bisbe et al. 2007). Therefore, further properties should be considered to ensure the quality of performance measurement. These properties include precision, sensitivity, and verifiability (Groen et al. 2017; Moers 2006).

Precision describes the lack of noise or variability of a performance measure (Banker and Datar 1989; Burkert et al. 2011). Therefore, precision implies the correct representation of what is to be measured. For accurate representation, there should be no uncontrollable factors for the subordinate that cause noise (Burkert et al. 2011). If a measure is not precise, a subordinate might be motivated to do the wrong things by false incentives (Kerr 1975; Merchant 1990). The variance of the actual performance can be demotivating for the subordinate, since performance is evaluated based on the incorrect measure or measures that the subordinate cannot influence (Moers 2006).

Sensitivity implies that the measure covers changes triggered by the subordinate's action (Burkert et al. 2011). Therefore, the effort level of the subordinates should be reflected in the indicator (Banker and Datar 1989; Burkert et al. 2011). Subsequently, if the subordinate improves his/her performance, the measure should increase as well (Moers 2006). If the measurement is not sensitive, this could be demotivating for the evaluated subordinate. 
Verifiability describes whether the measurement process is objective and verifiable by the subordinate (Moers 2006). Consequently, the subordinate should understand what the measure reflects and how it is calculated (Merchant 2006). In order to achieve objectivity, a measure should be collected and measured neutrally and free of subjective biases (Globerson 1985; Merchant 2006; Neely et al. 1997; Simons 1995). For subjective measures, actual performance may differ from measured performance (Merchant 2006; Simons 1995). Subjective measures are often associated with an inadequate response to the type of assessment. Subjective measures may make it difficult for subordinates to understand and have confidence in the measurements, potentially leading to a culture of excuses (Merchant and van der Stede 2017). Furthermore, subjective measures could lead to lenient ratings and less differentiation of users' performance (Moers 2005). However, using multiple performance measures can reduce the problems of subjectivity (Bommer et al. 1995; Henemann 1986; Henemann et al. 1987; Prendergast and Topel 1996).

The next property of the framework of Langevin and Mendoza (2013) only refers to the use of performance measures, which constitute one type of management control system. In particular, the framework recommends the use of multiple performance measures, because a single measure may not reflect the actual conditions accurately and therefore may not be perceived as fair (Langevin and Mendoza 2013). For example, a subordinate whose performance is only measured by single performance measures will maximize his/her bonus, which leads to single shortterm results (Ittner et al. 2003). Maximizing the bonus does not always reflect the increase in the companies' value. Therefore, management control systems should include both financial and non-financial measures to cover subordinates' performance more comprehensively (Burney et al. 2009; Ittner et al. 2003; Kaplan and Norton 1996).

A further property is participation in target-setting. Participation refers to the ability of a subordinate within a target-setting process to influence the objectives (Langevin and Mendoza 2013). This influence covers both the targets within their defined process and the control of the outcome (Brownell 1982; Langevin and Mendoza 2013; Milani 1975). Additionally, participation positively affects the perceived fairness of the measure because it causes subordinates to believe that their opinion is considered (Langevin and Mendoza 2013).

Feedback quality, the last property of the framework, relates to the managers' response to the subordinates' performance (Langevin and Mendoza 2013). This response should be clear, timely, and accurate (Magner et al. 2006). If there is a gap between the subordinate's behavior and the measurement, this can lead to less motivation and lower performance on the part of the subordinate (Merchant 2006). Furthermore, feedback should cover information about the subordinate's past behavior (Ilgen et al. 1979). In particular, consistency and accuracy are essential for the quality of feedback on a subordinate's performance, as the subordinate perceives the feedback as informationally fair within a feedback procedure (Roberson and Stewart 2006). Higher feedback quality is directly related to a greater trust of subordinates in the management control system (Hartmann and Slapničar 2009).

Currently, there is a discussion in the literature on management control systems. Specific mechanisms can be regarded as a bundle or as part of a system (Grabner 
and Moers 2013). Therefore, a particular management control system affects the perceived fairness and, thus, the attitude and behavior of the subordinate. Moreover, all management control systems and the resulting interdependencies affect the subordinate collectively. Consequently, other characteristics should be considered in addition to those listed by Langevin and Mendoza (2013).

\subsection{Theoretical framework - taking a management control perspective for analyzing properties of feedback mechanisms on digital platforms}

To analyze the effects of design characteristics on the function of feedback mechanisms, we take a management control perspective. Therefore, we use properties given in a management control literature as a link between specific design characteristics and function.

However, the properties within the management control literature, such as the framework identified by Langevin and Mendoza (2013) refer to the control or performance measurement of subordinates within an organization. In the context of feedback mechanisms of digital platforms, this subordinate exists only figuratively; that is, in this context, the term "subordinates" refers to the users who interact via the platform. The design of the feedback mechanism can affect only the operator of products or services (one-sided feedback) or the users of all market sides (multisided feedback). We translate the management control system properties (introduced in Sect. 2.2), to the context of feedback mechanisms with regard to the design characteristics (introduced in Sect. 2.1) because, similar to the organizational setting of the management control systems, the specific behavior of the users, or dysfunctional effects can be caused by design on the part of the operator. We do not transfer these dysfunctional effects to an instruction on how to give feedback, because the users react to certain arrangements, and by a specific design, these dysfunctional effects can be avoided in advance.

Based on differences between a subordinate and a user of a platform, there might also be differences or performance measures within organizations. Based upon the properties and the differences between feedback mechanisms and management control systems, we develop a theoretical framework, illustrate individual components, and discuss negative behavior of platform users caused by non-compliance with management control systems properties. These properties include precision (e.g., Burkert et al. 2011; Groen et al. 2017; Moers 2006), sensitivity (e.g., Burkert et al. 2011; Groen et al. 2017; Moers 2006), verifiability (e.g., Groen et al. 2017; Moers 2006), multiple performance measures (e.g., Klein et al. 2019; Langevin and Mendoza 2013; Ittner et al. 2003), participation in target setting (e.g., Langevin and Mendoza 2013), and quality of feedback (e.g., Klein et al. 2019; Langevin and Mendoza 2013; Magner et al. 2006; Roberson and Stewart 2006). Table 3 shows the properties of the framework with their explanations and differentiations from the properties of management control systems.

Precision within a feedback mechanism means that the low scores are not affected by noise (i.e., factors outside the control of the rated user). Depending on the feedback mechanisms' reciprocity, the mechanisms measure the performance of the 


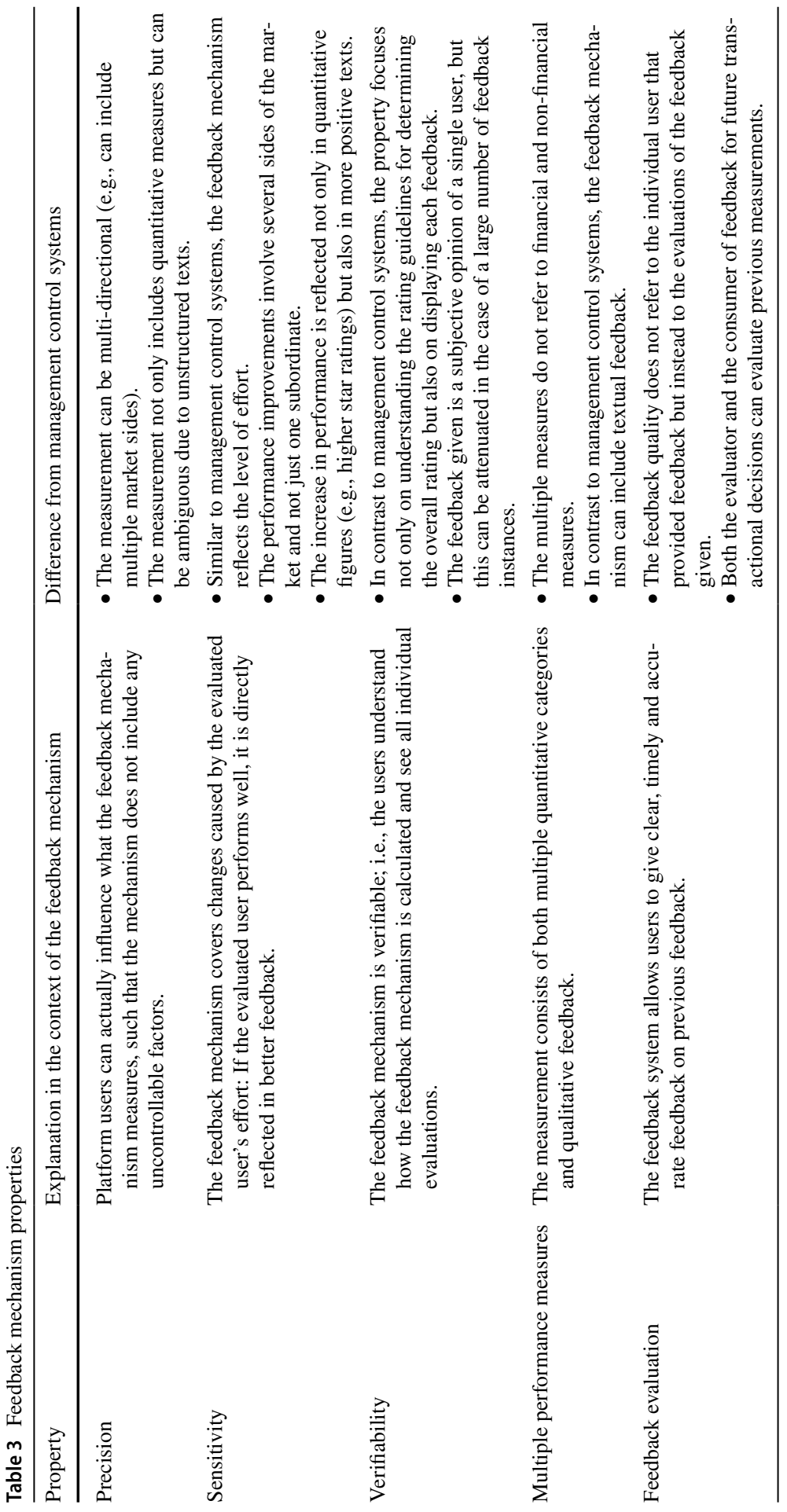


different market sides. If the measured submission categories are beyond the control of the rated users, and these users cannot influence the requirements, this can lead to non-compliance with the property. In addition to uncontrollable factors (e.g., submission categories beyond the user's control), noise can also result from qualitative feedback consisting of ambiguous texts (Mudambi et al. 2014), which in turn includes content that cannot be influenced. Precision is associated with the incentive to use performance measures (Moers 2006). Disregarding precision in the context of feedback mechanisms could, therefore, result in users using feedback neither to improve performance nor to decide on transactions. Consequently, the quality of the external resources would not increase.

Sensitivity is a property that is directly related to feedback mechanisms. Better performance of a platform's users should lead to better feedback. However, if sensitivity is not ensured, it might be demotivating, and users will no longer attempt to improve their performance. Since each piece of feedback is subjective, better performance should be represented by the diversity of provided feedback. For example, disregarding sensitivity leads to the evaluation not accurately reflecting the user's efforts. Although an improvement might not be reflected in every rating due to the subjectivity of single evaluations, an increase in performance should at least lead to a change in the overall rating. Depending on the mechanisms' reciprocity, this change should comprise all market sides included in the evaluation. Moreover, sensitivity could be affected by the scale level.

In the context of feedback mechanisms, verifiability implies that users should be able to understand each piece of feedback. Feedback only consisting of a summary of all given feedback is not verifiable, because the evaluated user does not know how the feedback mechanism calculates the overall rating. For instance, outliers could be present. In addition to the possibility of inspecting all single instances of feedback, the evaluated user should understand the scoring rule (i.e., how the overall rating is calculated). For example, each feedback could be weighted differently for various categories or their actuality. In such cases, users should understand how individual feedback or categories are included in the overall rating. Moreover, the use of the design characteristics filter, sorting, symbol, or color could affect the perception of the rating and thus the verifiability of a mechanism.

Due to the feedback being provided by the platform's users, personal feedback is not objective and represents a variety of different opinions. This subjectivity may cause demotivation (Ittner et al. 2003; Prendergast and Topel 1993). Also, tensions and anger can arise between users (Merchant and van der Stede 2017) and may even lead to favoritism (Prendergast and Topel 1996). Furthermore, the outcome effect and the hindsight effect could occur (Butler and Ghosh 2015; Ghosh 2005). However, this subjectivity might be reduced by the presence of a large amount of feedback and the use of a variety of measures.

Regarding feedback mechanisms, multiple measures require that the mechanism comprise several categories rather than only an overall rating. If there is only one overall rating within a feedback mechanism, no conclusion can be drawn about the actual score. For instance, if a user receives a rating of three on a scale of five, it is not clear whether the issue with the interaction was poor communication, poor service, or an unacceptable product. Therefore, this user does not know how to improve 
his/her performance and tries to maximize the overall rating without considering categories that are important for the entire platform ecosystem. Consequently, quantitative feedback should be kept simple by including multiple categories to help users understand the feedback and to ensure its quality. Unless several quantitative measures exist, feedback mechanisms should additionally include qualitative feedback. Similar to other management control systems, using various measures within a platform's feedback mechanism should help to decrease dysfunctional effects caused by subjectivity, such as favoritism.

In the context of feedback mechanisms, the property of target-setting differs from the target-setting within the performance measurement of subordinates. In the case of subordinates, managers can specify goals individually. Conversely, in the context of feedback mechanisms, operators can set minimum standards, but they do not define a specific target for users. Target-setting within qualitative feedback could include the limitation of negative feedback. Within quantitative feedback, performance is measured using predefined scales. The objective, in this case, is to receive the highest value on a given level. If the operator of a digital platform involves the users in the target-setting, this will result in specific benefits for many users. However, other users who are facing an interaction decision might no longer be able to compare users based upon feedback, which may result in an increase in search costs and weaken or remove the essential advantage of feedback mechanisms. In summary, users cannot participate in the objectives of the platform operator. Consequently, this control mechanism property is not transferable to platforms.

The property of feedback quality also exists within a platform's feedback mechanism. Feedback quality does not refer to the individual user that provided feedback but instead to the evaluations of the feedback given. For example, users can evaluate whether the feedback is useful or not. In particular, the quantification of the perceived usefulness of feedback is vital for future interaction decisions (Lee et al. 2018; Liu and Park 2015; Mudambi and Schuff 2010; Schindler and Bickart 2012). Like feedback from a manager on a subordinate's performance, platform users should provide feedback promptly and accurately. This kind of feedback is essential for users facing a transaction, because they put more weight on recent feedback (Bolton et al. 2004). Feedback evaluation helps to identify actual and accurate quantitative feedback. Since users do not directly consider temporal changes, this causes a self-selection bias in interaction decisions (Li and Hitt 2008). The evaluation of perceived usefulness by the platform's users sorts the comments with variable content according to their importance at low cost. This evaluation makes the comments that are identified as useful visible first, which can reduce the users' search costs, build reputation and trust, and reduce the cost of individual interactions ( $\mathrm{Ba}$ and Pavlou 2002; McDonald and Slawson 2002; Melnik and Alm 2002). Additionally, users can comment on qualitative feedback. Consequently, other users can use the feedback evaluation to check for feedback noise. 


\section{Method}

To answer our research questions, we conducted a descriptive analysis of various feedback mechanisms. We analyzed their characteristics and compliance with the standards. Based on the results of the descriptive analysis, we accomplished expert interviews to gain insight into the specific feedback mechanism and to unravel reasons for different choices.

\subsection{Descriptive analysis}

The theoretical framework was developed by translating standards given in the management control system literature to avoid dysfunctional effects such as negative attitudes and behavior. Our analysis focused on the feedback mechanism properties of precision, sensitivity, verifiability, multiple measures and feedback evaluation. However, we did not consider interdependencies with other management control systems.

Inspired by Steur and Bayrle (2020), we chose a selection principle similar to that of Dorfer (2016) to examine the specific platform feedback mechanisms' compliance with our theoretical framework design properties. The selection of platforms with a feedback mechanism to be evaluated was based on data from Alexa Internet Inc. Alexa provided a ranking of the most popular websites from Germany based on a global traffic panel consisting of millions of Internet users. The rank of each website was calculated using average daily visitors and the estimated number of page views over the last three months (Alexa 2018). We used the ranking of top sites in Germany on September 25th, 2018. The German ranking was chosen following Dorfer (2016). The restriction to the German ranking enabled a similar selection and helped to deal with legally dubious websites. The ranking, limited to 500 websites, was not representative of all platforms using feedback mechanisms. However, it was an approximate representation of the most popular sites and their corresponding business models in Germany (Becker et al. 2009; Dorfer 2016). Consequently, we assumed that the sample included the most important and widely used platforms, enabling us to cover a wide range of different platforms. Within this descriptive study, this approach provided internal validity and is free of bias (Dorfer 2016).

Starting from 500 websites, we selected relevant platforms using three steps and then evaluated their feedback mechanisms. Figure 1 illustrates the selection process of platforms with feedback mechanisms and the evaluation of these mechanisms. In particular, it shows the selection at the individual stages as well as the evaluation criteria of the unique properties. Appendix A shows the different websites and, where relevant, the specific reasons for exclusion.

First, we carried out a formal examination. We removed duplicates that used multiple domains. Websites with pornographic or legally dubious content were also excluded from the analysis, as cybercriminal activities were often associated with them (Dorfer 2016). To review the websites, we used the evaluations of Dorfer (2016) and Steur and Bayrle (2020) and web reputation tools such as Trend Micro Inc. and Web of Trust. Like Steur and Bayrle (2020), we excluded sites that did 


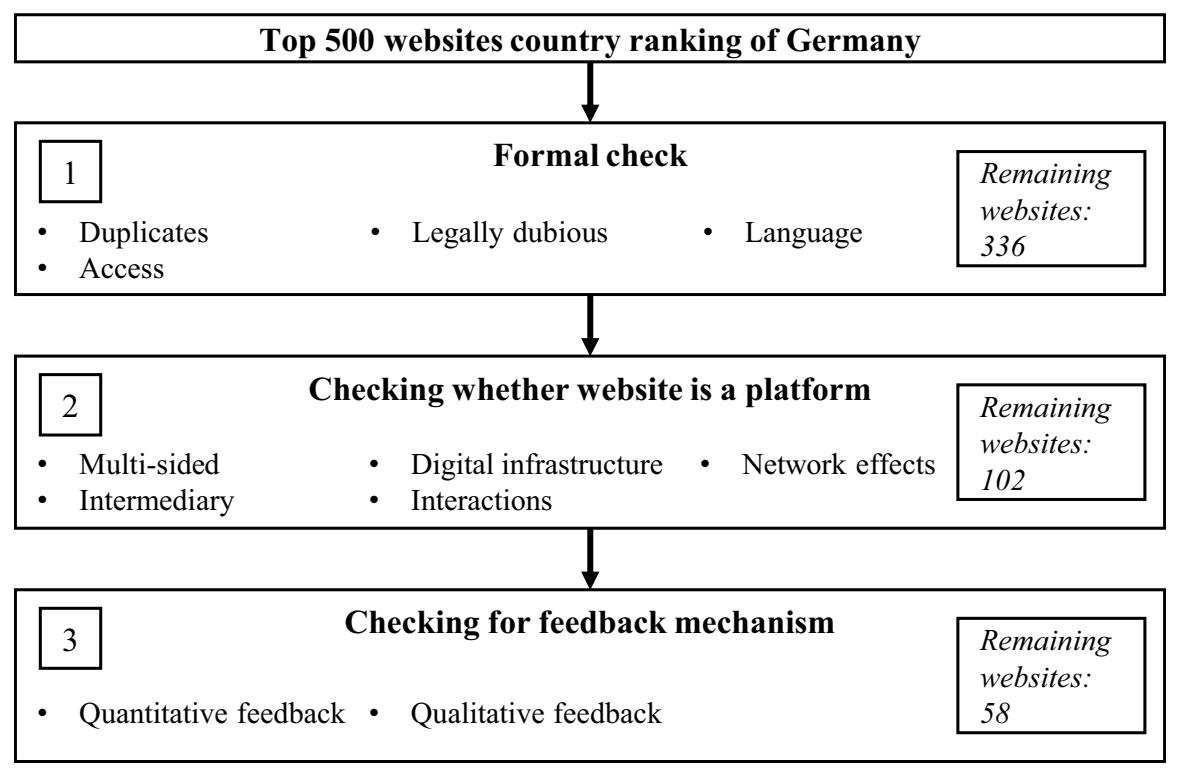

Fig. 1 Evaluation method

not offer a German, English or French version due to language limitations. We also excluded platforms that required confirmation of a Google account or phone number or that did not provide free access to the platform. There were three reasons for this exclusion: First, the websites without free access could not be checked for the presence of a platform-based business model. Second, we could not verify these websites for the presence of a feedback mechanism because this mechanism was only visible after logging in. Third, these websites could not be analyzed for compliance with the framework's properties.

In the next step, we checked the remaining 336 websites for the existence of a digital platform using the same characteristics than Steur and Bayrle (2020). In particular, a platform required the presence of two or more market sides, an intermediary providing a digital infrastructure, interactions between the different market sides, and network effects (Armstrong 2006; Brousseau and Penard 2007; Rochet and Tirole 2003; Tiwana 2014). For the selection, we used a similar classification of websites developed by Dorfer (2016). Editorial content websites, internet sites of non-profit organizations, mail services, online shops or internet sites of pipeline business models, online marketing domains for web tracking online converters, shortening and link management services and websites of (trans-) governmental institutions did not meet these criteria. Thus, we excluded these types of websites from further analyses. Website types that did represent a digital platform according to the criteria and thus are considered in the further evaluation are as follows: marketplaces, rating platforms, social media platforms, and travel platforms.

Next, we checked the remaining 102 platforms for the existence of a feedback mechanism. For the presence of a feedback mechanism, a qualitative or quantitative 
mechanism, recognizable by a comment function or different symbols, had to be present. Following the platform selection, we analyzed the properties of the remaining 58 platforms' feedback mechanisms. The final analysis of the properties was conducted in summer 2019. In a detailed analysis, we categorized the platforms according to their types. For this purpose, we used the different types that we classified in step two. Appendix B summarizes the platforms with a feedback mechanism and the type of platform.

Within the analysis, we used existing items from the management control systems literature to assess the applicability of the frameworks' properties. All measurement instruments are presented in Appendix C. To check for precision, sensitivity, and verifiability, we used items developed by Moers (2006) that had already been used by other authors such as Burkert et al. (2011) and Groen et al. (2017). Since we utilized single items within the analysis, we selected the particular items of the management control systems quality in accordance with Groen et al. (2017). Groen et al. (2017) also analyzed the precision, sensitivity, and verifiability of single items based on the constructs of Moers (2006). The item for precision related to feedback mechanisms that only measure what the evaluated user can influence. The item for sensitivity referred to the fact that excellent performance of the evaluative user is directly reflected in better feedback. The item of verifiability applied to the measurement of user performance being verifiable.

We checked multiple measures using a construct based on Widener (2006), who provides a questionnaire to analyze the use of management control systems in bonus compensation. In particular, Widener (2006) examined plans that include both financial and non-financial measures. Other authors such as Klein et al. (2019) used the items for multiple measures. In the context of feedback mechanisms, the multiple measures item indicates that the mechanism is based on both multiple quantitative and qualitative measures. We constructed the item on evaluating feedback according to Hartmann and Slapničar (2009). More precisely, we used question five of their questionnaire as a reference. The item feedback evaluation covered users who had given useful evaluations on previous feedback.

The evaluation of the measuring instruments was not carried out based on a survey of the platform operators or the users. Instead, we evaluated the instruments ourselves. For this purpose, we collected information about the feedback mechanisms on the respective websites provided by the platform operators and examined the structure and design of the previously offered feedback. For a better understanding of each platform's feedback mechanism, we provided feedback ourselves. Subsequently, we could assess the items. We conducted several steps to ensure reliability. First, two researchers conducted an independent analysis of the platforms. Then, the results were compared, discussed several times, and the platforms were rechecked.

In addition to the properties of our framework, we analyzed the feedback mechanisms of the selected platforms concerning their design characteristics. This analysis provides an overview of the analyzed feedback mechanisms. In particular, we examined the frequency and portion of the feedback characteristics 
introduced in Table 2. The analysis of the reciprocity, query method, submission categories, feedback evaluation, filter, and sorting involved the entire sample of 58 platform feedback mechanisms. The symbols, colors, and scale levels, however, applied only to the quantitative feedback display. Therefore, our examination only included a sample of 56 platforms. We did not check the design characteristic "submission restriction" of the feedback mechanisms because the analysis of this characteristic required the execution of transactions on each platform.

\subsection{Qualitative analysis}

In addition to the descriptive approach, we chose to use a qualitative research approach (Yin 2009) based on interviews to identify reasons for different design approaches for a feedback mechanism. Specifically, we used a cross-case analysis (Eisenhardt 1989). Therefore, we were able to compare the results among different platforms. The information from all interview transcripts was first synthesized, and the transcripts were analyzed using selective coding. We chose selective coding due to the late period in the study, and the different categories resulted from the descriptive analysis that needed further explanations (Corbin and Strauss 1990).

Therefore, we developed a semi-structured interview to include the three categories remaining from the descriptive analysis:

- application of a feedback mechanism,

- characteristics of feedback mechanism,

- feedback mechanism properties.

Within the interviewee selection process, we ensured that the interview partners were part of a platform and thus complied to the same criteria as the platforms within the descriptive analysis. Furthermore, our study focused on companies located in the DACH-region (at least one subsidiary) and covered platforms from different industries. To find reasons why platforms used or did not use feedback mechanisms, the analysis included platforms that currently did not use a feedback mechanism. In total, we contacted 87 platforms and requested for interviews, which resulted in 14 interview partners. Five platforms did not use any feedback mechanism. The interviews were conducted by telephone, recorded and transcribed in autumn 2019 and lasted between 32 and $88 \mathrm{~min}$, with an average of $60 \mathrm{~min}$. To avoid misunderstandings, we then sent the transcripts to the interviewees, who rechecked the transcripts. Table 4 gives an overview of the anonymized interviewees, their platform type, their foundation date, number of employees, the revenue of the platform, and whether they used a feedback mechanism.

In order to ensure the reliability of the data, two researchers conducted the data analysis independently. We then compared and discussed the emerging results several times. These emerging results were mostly similar. Appendix D provides an overview of the individual categories, the associated constructs and corresponding examples. 


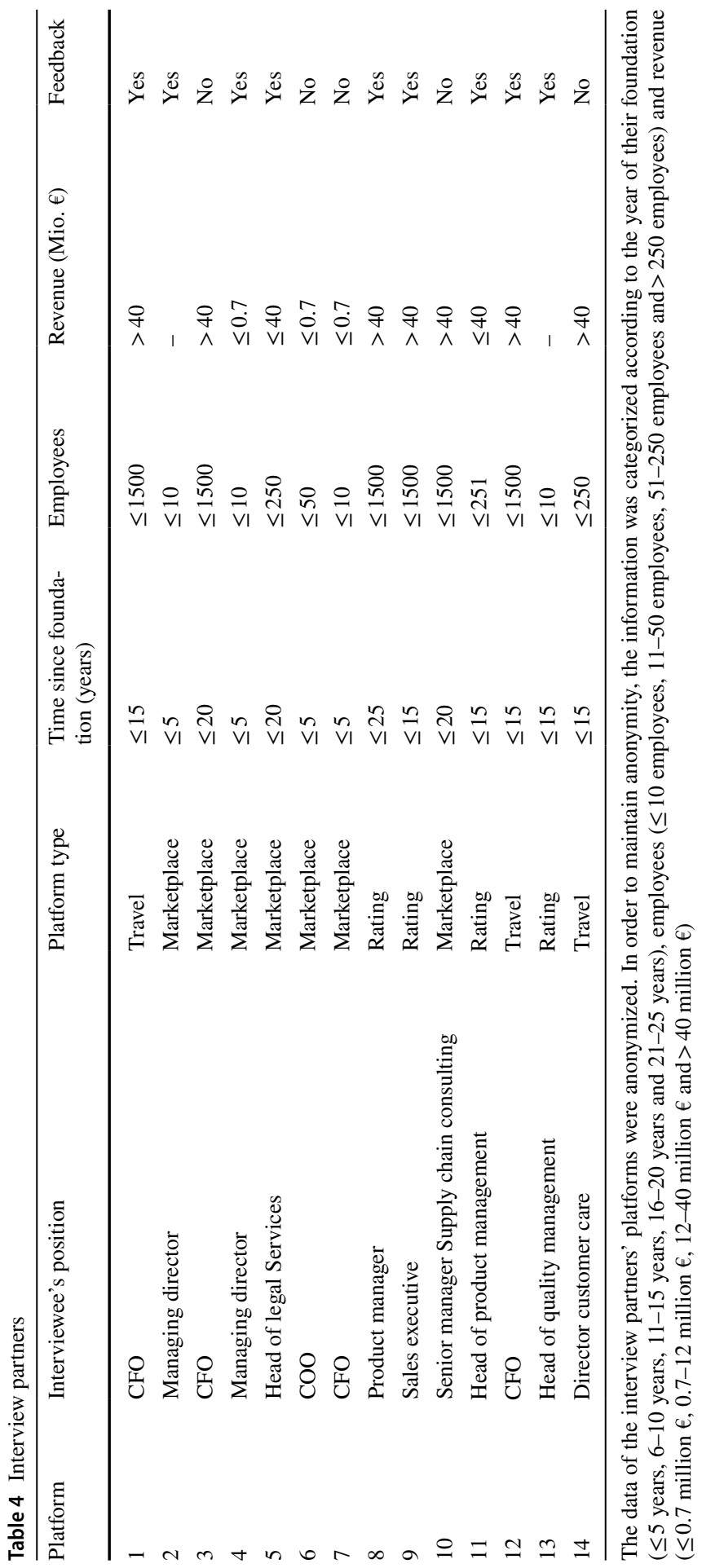


Table 5 Frequency of feedback design characteristics within our sample

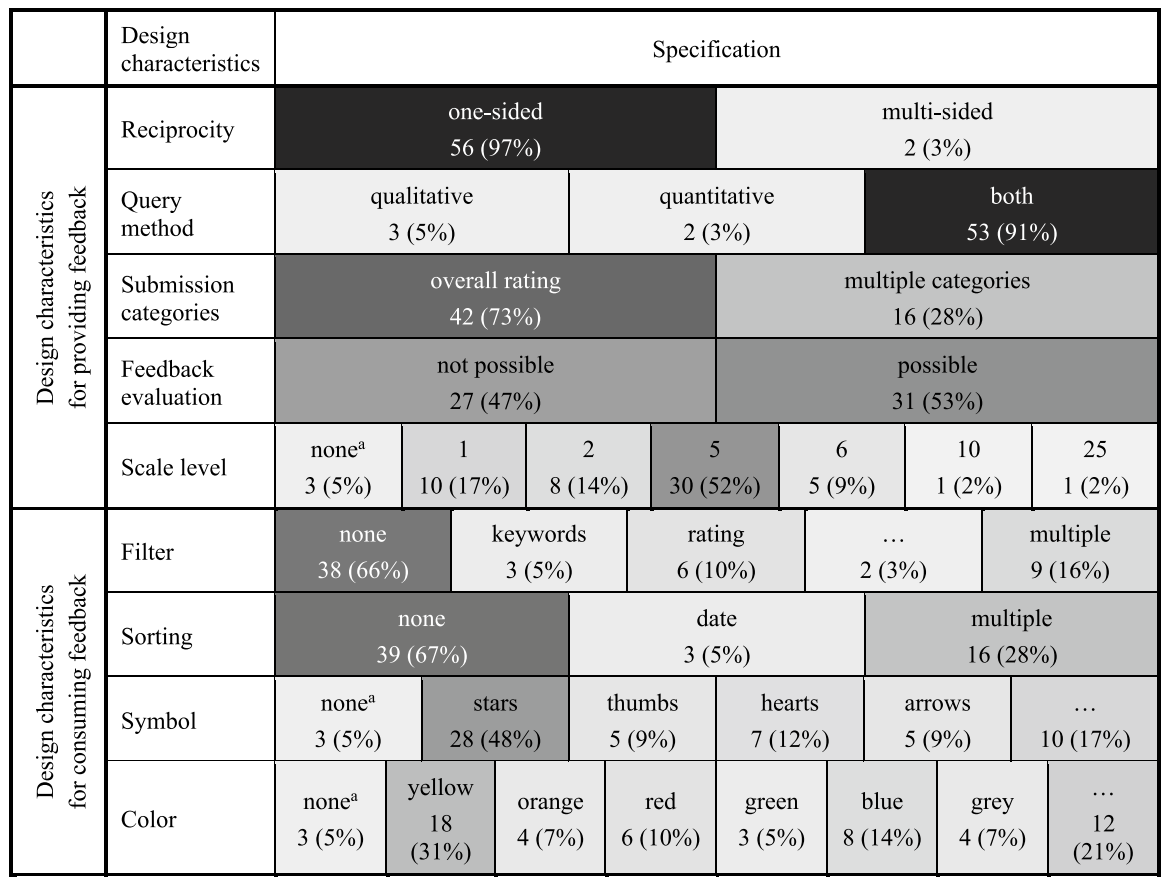

${ }^{a}$ Within this specification, there is only qualitative feedback. Therefore, no predefined scale, no symbol or different colors are used to represent the feedback.

\section{Results}

\subsection{Results of the descriptive analysis}

The frequency of design characteristics containing the absolute and relative frequencies examined in 58 platform feedback mechanism are shown in Table 5.

Descriptive analysis reveals that $57 \%$ of the analyzed digital platforms use a feedback mechanism. A further examination of the design of the individual feedback types reveals that only $3 \%$ of digital platforms use multi-sided feedback. There are differences in the method within the feedback mechanisms. Most platform feedback mechanisms have both qualitative and quantitative elements (91\%). A few (8) platforms use either qualitative or quantitative parts. In particular, $5 \%$ of digital platforms only use qualitative feedback, whereas $3 \%$ only use quantitative feedback options. Within the qualitative feedback, there are differences in the maximum number of characters. However, most feedback mechanisms (73\%) contain only an overall rating. The remaining platforms use up to 12 categories within the feedback. Feedback evaluation is possible on $53 \%$ of the platforms. The scales used within the quantitative components also vary and consist of up to 25 levels. However, most digital platforms with a feedback mechanism use a five-point scale (52\%). 
In our sample, $66 \%$ of the platforms do not use a filter. Some platforms classify qualitative feedback by keywords (e.g., Amazon's marketplace). Five platforms provide an overview of the top terms within the qualitative part of their feedback mechanism. However, one of these platforms offers an additional filter corresponding to the rating. The filter by rating is provided by $10 \%$ of the platforms. Also, this filter is used in combination with other filters. In addition to the rating, these filters include language (two platforms), transaction type (two platforms), photos (one platform) or date (one platform). Further, filters within feedback mechanisms include the transaction type and the submission categories (one platform each). The platforms also offer different forms of sorting (33\%). These forms include multiple sorting (28\%) in addition to the date (5\%). The date is involved in all offered filters. Other filters include rating, usefulness, language, user activity, photos, and videos.

Digital platforms use star symbols most frequently (48\%). Heart symbols (12\%), arrow symbols (9\%), and thumb symbols (9\%) are used less commonly. Platforms most often use a yellow color $(31 \%)$ followed by a blue color $(14 \%)$ for the symbols within their feedback mechanism.

The explorative analysis shows different compliance of the platforms with the properties, as well as also differences between platform types (Table 6).

Most platforms comply with sensitivity (55 platforms) and verifiability (56 platforms). Platforms less often comply with the other properties. For instance, almost half of the platforms use feedback evaluation, while precision and multiple measures are rarely considered. In particular, only seven feedback mechanisms comply with precision, and 17 feedback mechanisms achieve multiple measures.

We find further differences in compliance with the properties of our framework between different platform types. However, these differences are not apparent with regard to sensitivity and verifiability, as almost all platforms fulfil these properties. Instead, we find differences in precision and multiple measures. Only one of the social media platforms achieves both properties. In contrast, some of the marketplaces, rating platforms and travel platforms fulfil precision (18-22\%) and the multiple measures (44-100\%).

To obtain first indications about the possible interrelations between the properties, we analyze their co-occurrence (Table 7).

Co-occurrence analysis shows further results. For example, whenever a feedback mechanism complies with precision, the mechanism also fulfills sensitivity, verifiability and multiple measures. The feedback evaluation also often co-occurs with

Table 6 Properties' compliance corresponding to the platform type

\begin{tabular}{l|rrrrrrrrrrr}
\hline & \multicolumn{1}{|l}{ Precision } & \multicolumn{2}{l}{ Sensitivity } & Verifiability & \multicolumn{2}{l}{$\begin{array}{l}\text { Multiple } \\
\text { measures }\end{array}$} & \multicolumn{2}{l}{$\begin{array}{l}\text { Feedback } \\
\text { evaluation }\end{array}$} & $\#$ \\
\hline Marketplace & 3 & $(18 \%)$ & 17 & $(100 \%)$ & 17 & $(100 \%)$ & 8 & $(47 \%)$ & 8 & $(47 \%)$ & 17 \\
Rating & 2 & $(22 \%)$ & 8 & $(89 \%)$ & 8 & $(89 \%)$ & 4 & $(44 \%)$ & 5 & $(56 \%)$ & 9 \\
Social media & 1 & $(4 \%)$ & 26 & $(93 \%)$ & 27 & $(96 \%)$ & 1 & $(4 \%)$ & 15 & $(54 \%)$ & 28 \\
Travel & 1 & $(25 \%)$ & 4 & $(100 \%)$ & 4 & $(100 \%)$ & 4 & $(100 \%)$ & 2 & $(50 \%)$ & 4 \\
\hline$\sum$ & 7 & $(12 \%)$ & 55 & $(95 \%)$ & 56 & $(97 \%)$ & 17 & $(29 \%)$ & 31 & $(53 \%)$ & 58 \\
\hline
\end{tabular}


Table 7 Co-occurrence of properties' compliance

\begin{tabular}{l|lllllllllll}
\hline & \multicolumn{2}{|l}{ Precision } & \multicolumn{2}{c}{ Sensitivity } & Verifiability & \multicolumn{2}{l}{$\begin{array}{l}\text { Multiple } \\
\text { measures }\end{array}$} & \multicolumn{2}{l}{$\begin{array}{l}\text { Feedback } \\
\text { evaluation }\end{array}$} \\
\hline Precision & $\mathbf{7}$ & & 7 & $(100 \%)$ & 7 & $(100 \%)$ & 7 & $(100 \%)$ & 5 & $(71 \%)$ \\
Sensitivity & 7 & $(13 \%)$ & $\mathbf{5 5}$ & & 54 & $(94 \%)$ & 17 & $(28 \%)$ & 30 & $(48 \%)$ \\
Verifiability & 7 & $(13 \%)$ & 54 & $(96 \%)$ & $\mathbf{5 6}$ & & 17 & $(30 \%)$ & 31 & $(55 \%)$ \\
Multiple measures & 7 & $(41 \%)$ & 17 & $(100 \%)$ & 17 & $(100 \%)$ & $\mathbf{1 7}$ & & 11 & $(65 \%)$ \\
Feedback evaluation & 5 & $(16 \%)$ & 30 & $(97 \%)$ & 31 & $(100 \%)$ & 11 & $(35 \%)$ & $\mathbf{3 1}$ & \\
\hline
\end{tabular}

Bold values imply the frequency of the respective properties. The relative frequencies of the individual properties in each row are calculated using the respective bold value

precision $(71 \%)$. In addition to precision, verifiability is usually satisfied if sensitivity is met. However, precision (13\%), multiple measures (28\%), and feedback evaluation (48\%) rarely co-occur with sensitivity. The same results are obtained in relation to the co-occurrence of verifiability. Sensitivity (96\%) often co-occurs, while precision (13\%), multiple measures (30\%), and feedback evaluation (55\%) cooccur less frequently. Multiple measures often coincide with sensitivity, verifiability (100\% each), and feedback evaluation (65\%). However, precision rarely co-occurs (41\%). Likewise, we observe a concomitant presence of the feedback evaluation and precision (16\%). Sensitivity (97\%) and verifiability (100\%) often occur concurrently, compared to rare co-occurrence with precision and multiple measures.

\subsection{Results of the interviews}

This section contains the main findings of the interviews for three categories "application of a feedback mechanism", "design characteristics of feedback mechanisms", and "feedback mechanism properties", which are summarized in Table 8. In detail, we present the results for the individual categories.

Table 8 Results of each category

\begin{tabular}{ll}
\hline Application of a feedback mechanism & $\bullet$ Behavior control \\
& $\bullet$ The development stage of the platform \\
& $\bullet$ Implementation and monitoring costs \\
& $\bullet$ Other control mechanisms \\
& $\bullet$ Platform type and variety of its supply \\
& $\bullet$ Other platforms \\
Design characteristics of feedback mechanisms & $\bullet$ Detailed information vs simplicity \\
& $\bullet$ Psychological factors \\
Feedback mechanism properties & $\bullet$ Customer experience vs accessibility \\
& $\bullet$ Detailed information vs simplicity \\
& $\bullet$ Invested time and capital of users \\
& $\bullet$ Supply and diversity \\
\hline
\end{tabular}




\subsubsection{Application of a feedback mechanism}

The analysis shows several results regarding the implementation of feedback mechanisms. The results include reasons for but also arguments against the use of feedback mechanisms. One issue that interviewees mention as a reason for introducing a tool is the control of user behavior. The experts point out that feedback mechanisms are primarily related to trust. They justify this argument with the importance of social proof, which implies that users increasingly base their transaction decisions on customer ratings and have more confidence in them than in advertising. The experts assess the feedback mechanisms as necessary not only for users' decisions regarding transactions but also for the behavior of the suppliers. For example, platform 12 mentions that their "suppliers are very curious about the feedback, especially why and what kind of feedback they get". A further point about behavior control is the infrastructure used, such as mobile devices. In this context, platform 8 notes that "the faster people are asked for feedback, the more people give feedback."

However, behavior control can also be used as an argument against the application of a feedback mechanism. Platform 14 explains that they do not use a feedback mechanism because users are very price-sensitive and tend to base their decision on price. Therefore, feedback would not be used for a transaction decision. Further, platform 1 names a negative effect on the conversion rates as a further argument against the usage of a feedback mechanism. Platform 10 mentions another argument against using a feedback mechanism, stating that they do not use any feedback mechanism because "the users were in contact before using the platform". As a further argument, platform 14 states that there are few suppliers within their branch. If platform 14 had a feedback mechanism and one of the providers got a lot of bad ratings, platform 14 would have to remove that provider. However, this would result in losing a significant part of the offering and content, which would be a considerable disadvantage compared to other competitors.

Another argument against the use of a feedback mechanism represents the development stage of the platform. According to the experts, many platforms are still in the early stages of their development and have therefore not yet implemented a feedback mechanism. For instance, platform 6 states that for the use of "automatic mechanisms, you first need a critical mass [of users], which we do not have at present." Moreover, the interviewees argue that a platform first needs a sufficient number of users on the platform. Considering a limited budget, the operator focuses on this task first and tries to acquire users. Once sufficient transactions have been made, and sufficient feedback can be obtained, it seems reasonable to introduce a feedback mechanism.

The costs of implementation and monitoring also contribute to the experts' decision regarding whether to use a feedback mechanism. The experts argue that the mechanism must be integrated procedurally into the platform and that this carries development costs. Besides the implementation, the feedback mechanism also involves rating costs for users, such that some platforms worry about extreme ratings (e.g., only positive and negative feedback). For instance, platforms 9 and 13 
recognize such extreme ratings (e.g., $80 \%$ of their ratings are positive, and a relevant number of ratings are negative). However, the submission of feedback is not a problem, which is attested to by a relatively good response rate (e.g., $7 \%$ to $14 \%$, platform 9). A further aspect of the application of a feedback mechanism is the cost of handling manipulated feedbacks. For instance, platform 9 uses "a large number of software programs that detect manipulation and prevent such ratings from going live at all" and has a separate compliance department, which takes care of manipulations.

The use of other control mechanisms is another explanation for the lack of use of feedback mechanisms. For example, platforms 3 and 10 state that they do not use a feedback mechanism, as they use performance measures or other control mechanisms of supplier evaluation to ensure quality. Platform 3 prefers to use performance measures to provide its suppliers with reliable and objective information.

Moreover, the platform type and the variety of supply are reasons against the application of a feedback mechanism. For instance, platform 3 does not use a feedback mechanism because, in their business-to-business environment, there are few transactions per product offered and the customer of a product is not necessarily the user of that product. However, the platform type can also be a reason for using a feedback mechanism, as this mechanism is part of the business model of rating platforms. In addition to the platform type, the need for an explanation of the products and services offered is a reason for not using a feedback mechanism.

Table 9 Frequency of feedback design characteristics within the interviewees' mechanisms

\begin{tabular}{|c|c|c|c|c|c|}
\hline & $\begin{array}{l}\text { Design } \\
\text { characteristics }\end{array}$ & \multicolumn{4}{|c|}{ Specification } \\
\hline \multirow{5}{*}{ 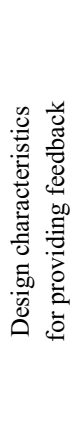 } & Reciprocity & \multicolumn{2}{|c|}{$\begin{array}{l}\text { one-sided } \\
8(89 \%)\end{array}$} & \multicolumn{2}{|c|}{$\begin{array}{c}\text { multi-sided } \\
1(11 \%)\end{array}$} \\
\hline & $\begin{array}{l}\text { Query } \\
\text { method }\end{array}$ & \multicolumn{4}{|c|}{$\begin{array}{c}\text { both } \\
9(100 \%)\end{array}$} \\
\hline & $\begin{array}{l}\text { Submission } \\
\text { categories }\end{array}$ & \multicolumn{2}{|c|}{$\begin{array}{c}\text { overall rating } \\
3(33 \%)\end{array}$} & \multicolumn{2}{|c|}{$\begin{array}{l}\text { multiple categories } \\
\qquad 6(67 \%)\end{array}$} \\
\hline & $\begin{array}{l}\text { Feedback } \\
\text { evaluation }\end{array}$ & \multicolumn{2}{|c|}{$\begin{array}{c}\text { not possible } \\
6(67 \%)\end{array}$} & \multicolumn{2}{|c|}{$\begin{array}{l}\text { possible } \\
3(33 \%)\end{array}$} \\
\hline & Scale level & \multicolumn{2}{|c|}{$\begin{array}{c}5 \\
8(89 \%)\end{array}$} & \multicolumn{2}{|c|}{$\begin{array}{c}6 \\
1(11 \%)\end{array}$} \\
\hline \multirow{4}{*}{ 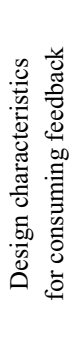 } & Filter & $\begin{array}{c}\text { none } \\
3(33 \%)\end{array}$ & $\begin{array}{c}\text { rating } \\
2(22 \%)\end{array}$ & $\begin{array}{c}\text { type of evaluator } \\
1(11 \%)\end{array}$ & $\begin{array}{l}\text { multiple } \\
3(33 \%)\end{array}$ \\
\hline & Sorting & \multicolumn{2}{|c|}{$\begin{array}{c}\text { none } \\
4(44 \%)\end{array}$} & \multicolumn{2}{|c|}{$\begin{array}{l}\text { multiple } \\
5(56 \%)\end{array}$} \\
\hline & Symbol & \multicolumn{2}{|c|}{$\begin{array}{c}\text { stars } \\
7(78 \%)\end{array}$} & $\begin{array}{l}\text { quare } \\
(11 \%)\end{array}$ & $\begin{array}{l}\text { multiple } \\
1(11 \%)\end{array}$ \\
\hline & Color & $\begin{array}{c}\text { yellow } \\
2(22 \%)\end{array}$ & $\begin{array}{l}\text { orange } \\
2(22 \%)\end{array}$ & $\begin{array}{c}\text { black } \\
2(22 \%)\end{array}$ & $\begin{array}{l}\text { multiple } \\
3(33 \%)\end{array}$ \\
\hline
\end{tabular}




\subsubsection{Design characteristics of feedback mechanisms}

In the next step of our analysis, we obtain the frequency of the design characteristics of feedback mechanisms (Table 9). For example, only platform 2 uses a multi-sided mechanism, noting that "there are always two sides involved in the trade. Therefore, both sides should have the possibility to evaluate the trade." All platforms use both qualitative and quantitative feedback. Most platforms even have several categories. However, most of the platforms have not implemented the feedback evaluation. Almost all platforms use a scale of five with stars. In contrast, the color used within the mechanism varies. Additionally, most platforms use one or more filters. In terms of sorting, the platforms either have multiple sorting options or do not use any sorting.

In addition to the frequencies, the interviews also reveal reasons for the use of individual design characteristics. These reasons include other platforms, detailed information vs simplicity, psychological factors, and implementation and monitoring costs.

Most interviewees use other platforms as inspiration or have even copied the mechanism of another platform. The experts cite Amazon, Booking.com and eBay as examples of inspiration. Platform 12 went one step further and even "hired people who previously worked at Amazon". This orientation towards other platforms is the main reason for the use of multiple categories and star symbols. For instance, platform 2 claims that they use stars because "they are also used on Amazon and eBay". The orientation to other platforms clarifies the example of platform 11, which previously used black stars. They are currently switching to yellow stars "because they are the common standard and users have learned this". In summary, the interviewees name the well-established status, the popularity among users, and the simple and fast development of the mechanism as reasons for inspiration.

The experts highlight the trade-off between detailed information and simplicity as another essential factor in designing the feedback mechanism. This trade-off includes the design characteristics of query method, submission categories, scale level, filter, sorting, symbols, and colors. For instance, a simple design should "keep the barriers [to providing feedback] low" (platform 4) and should help to get more feedback. Moreover, this trade-off also refers to users deciding on a transaction and needing detailed information. For example, the experts mention an adverse effect of individual design characteristics (e.g., filters and sorting) on conversion rates as a reason for the design of a feedback mechanism.

To create simplicity, platform 1 is switching to mobile-first so that an app will display the complete transaction. App users are less willing to write text; therefore, the experts plan to introduce several quantitative criteria. The experts explain that spoken feedback also plays a role in this transition. Additionally, simplicity is also related to the platform's decision regarding the cost of development and the value added by the particular design characteristics. For instance, the experts argue that a filter might not be used because relevant groups or filter categories first have to be defined, which could be very expensive, in the case of high product variety.

Psychological factors are listed as further factors for using symbols and colors. Platform 2, for example, states that they chose their color because it is 
"complementary to our other colors [...] [and the displayed feedback] is not a rating of our platform". Moreover, the experts claim that yellow stars reflect a kind of value and should symbolize trust. The colors should also support the users in their perception of the feedback. While red indicates a problem, green indicates that everything is okay.

\subsubsection{Application of feedback mechanism properties}

None of the platforms take the feedback mechanism properties such as precision into account in the design of their mechanisms. However, the interviews indicate that customer experience vs accessibility, detailed information vs simplicity, and supply and diversity are crucial factors in terms of compliance with feedback mechanism properties.

An essential factor for the interview partners is the trade-off between customer experience and accessibility. The customer experience is composed of many variables and of variables that the supplier, cannot control, so the customer experience and accessibility differ (platform 10). For instance, the experts argue that the evaluators should understand the supplier's business model to assess criteria that can be influenced. Moreover, the rare compliance with feedback evaluation within our descriptive analysis could result from an unclear assignment of the most helpful feedback for the decision and the fact that users base their decision on several instances of feedback (platform 3).

Furthermore, the experts explain the rare compliance of feedback mechanisms with precision and multiple measures within the descriptive analysis using the tradeoff between detailed information and simplicity. For example, they note that if precision is fulfilled, the provision of feedback is more complicated, which in turn leads to higher rating costs compared to feedback mechanisms that do not comply with this property. Also, the interviewees mention the faster provision of feedback and the associated evaluation costs as reasons not to comply with the multiple measures. In contrast, the compliance with multiple measures even makes it possible to get detailed information and to compare it with aspects that are important to a user (platform 11).

Another explanation for compliance with feedback mechanism properties is the time and capital invested by users. In particular, these reasons emerge about different platform types. The experts attribute spent time and money both to the use of transaction decisions and to the provision of feedback. For example, the experts state that trips are only made once a year and that this typically involves higher invested capital than in many marketplaces. In this case, the user wants to get as much information as possible about what he or she is spending his or her money on and thus reads the previous evaluations very carefully. The users also honor this information requirements in the feedback. The higher the invested capital, the more aware users are of the importance of feedback and the more willing they will be to give more detailed feedback.

According to the interviewees, the supply and diversity of products and services offered on the platform are essential factors in the fulfilment of the feedback mechanism properties (i.e., precision and multiple measures). In terms of precision, 
platform 3 mentions that it is difficult for operators to define standardized, influenceable rating categories due to the variety of products. According to platform 5, the precision depends on whether the supplier offers the complete service itself and can thus also influence the complete outcome. Also, platform 8 attributes the fulfilment of this property to the emotionality of the products. Platform 5 identifies the degree of personality as another reason for compliance with multiple measures. The more personal the performance is, the more detailed and differentiated the feedback has to be, or the more open the users are providing detailed feedback. In contrast, within social media platforms, getting feedback is more critical than within the other platform types. Therefore, social media platforms might not comply with precision or multiple measures to get more feedback and a higher distribution reach of the posts on the platform (platform 14).

\section{Discussion}

Some of our results are counterintuitive. The rare application of feedback mechanisms is surprising considering the relevance of feedback mechanisms for a platform's control, as mentioned by Kornberger et al. (2017). The limited use is unexpected because some authors, such as Bolton et al. (2004) and Resnick and Zeckhauser (2002), have found out that feedback mechanisms have a positive influence on trust in the market or the platform and thus on the respective price and transaction volume. However, the interviews reveal the reasons for this low usage. The example of Uber provides a further explanation, as Uber's users do not use the given feedback when making decision interactions (Knee 2018). This illustrates that the success of a platform does not necessarily require a feedback mechanism in all cases. Subsequently, we recommend that platform operators check whether their users use feedback mechanisms for their transaction decision, so as to analyze their impact on conversion rates. If they have enough users (i.e., users who could give feedback), they should introduce a feedback mechanism.

Moreover, the rare use of multi-sided feedback is surprising. However, the example of Amazon's marketplace could provide further insights. Amazon's marketplace uses other intermediaries (e.g., Visa) to ensure payment and to avoid opportunistic behavior of one market side. Consequently, the additional intermediary guarantees that the respective user of a market side fulfils his/her obligations. Therefore, the operator has more information than the customer and could behave opportunistically. The feedback mechanism should reflect this information asymmetries based on previous transactions and reduce information asymmetries. A reciprocal feedback mechanism is only necessary if users of one market side have more information than users of the other market sides and there might be opportunistic behavior by more than one side. Within the platform Airbnb, for instance, guests can act opportunistically by destroying the inventory or by polluting the apartment. Feedback mechanisms might help to prevent such cases before the transaction.

The low use of reciprocal feedback confirms the results found by Bolton et al. (2013). Within complementary feedback mechanisms, which inform users about the feedback immediately after the submission, there is dysfunctional user behavior. In 
this case, the feedback neither improves users' performance nor supports users in deciding on interactions. Subsequently, there is no overall improvement in the value creation of the platform. Within two-sided blind feedback or an additional onesided feedback option for customers, operators can avoid this misconduct, even if the amount of provided feedback is lower than without the restriction (Bolton et al. 2013). Despite the popular feedback mechanisms designs to prevent the disadvantages of reciprocal feedback, future research can examine when platform operators should use one-sided and multi-sided feedback mechanisms. Due to the well-known behavior within reciprocal mechanisms, we propose that operators in the next step should check how the information asymmetries are distributed. If these asymmetries are only distributed to one market side, the operator should first use a one-sided mechanism. However, if a reciprocal mechanism is used, we recommend using double-blind feedback or even a detailed seller rating in accordance with Bolton et al. (2013).

The frequent use of star symbols is consistent with the findings of Sparling and Sen (2011), who also reported that the star is the most preferred symbol. Unlike in Sparling and Sen (2011), thumb symbols are rarely used in our sample, and heart symbols are used frequently. Most of the experts mention the simplicity and popularity of the symbols as a reason for their frequent use. On the one hand, this result is expectable, since the Internet offers maximum transparency, and therefore competitors can use the same symbols relatively easy. On the other hand, it is surprising that the operators rarely think about the effect of the choice of the symbols on users' behavior (except for the conversion rates). Not to limit the feedback mechanism using star symbols within the feedback mechanisms simply because most other platforms seems to be an interesting approach. Star symbols could be used in a first version but should be evaluated thereafter for their impact on providing feedback and transaction decisions (e.g., conversion rates).

Since users often give extreme ratings (i.e., if they are very satisfied or very dissatisfied) (Dellarocas and Wood 2008), the frequent use of a five-point-scale is unexpected (as, e.g., "very satisfied" and "very dissatisfied" can be shown on a twopoint scale). The rare use of scales with more than five levels can be explained by the higher rating costs (Sparling and Sen 2011). Nevertheless, a scale level of two could be used more frequently. The evaluation costs for the users would be lower, and many ratings in the middle of the scale (e.g., level 3 in a 5 point scale) (Sparling and Sen 2011) could be avoided. Likewise, such a scale can prevent extreme ratings, such as in the case of Airbnb and TripAdvisor, where the users have a proportionally high average score of over 4.5 on a five-point scale (Zervas et al. 2015). We suggest operators not merely to adopt a scale of five from other operators within the mechanism. Rather, they should consider the impact of the scale used on the provision of feedback. In the case of extreme ratings, for example, the scale could be reduced to two levels. However, since few experts assess extreme scores, most of them notice normal distribution, and non can see a negative impact on submission, the five-point scales seems to be a good starting point.

The rare compliance with precision is unexpected in the first place and could explain the negative attitude and behavior of users reported by Abramova et al. (2016). However, the need for influenceable factors is controversial topic in the 
literature. For instance, Klein et al. (2019) found that the application of controllability is not significantly related to perceived justice. Although controllability is regarded as necessary, it is rarely used in practice due to its complexity and uncertainty. Controllable measures are optimal for the subordinate, but not for the entire organization, so uncontrollable factors must be measured to bring these factors into focus (Burkert et al. 2011). Differences in the application of controllability exist with regard to the subordinate. To achieve complete leadership and to draw the attention of a subordinate to critical points, subordinates could use noninfluenceable categories (Burkert et al. 2011). Moreover, platform operators could deliberately use non-influenceable categories because they want to set incentives for investment in innovations (Boudreau 2010). The low co-occurrence of multiple measures and precision, as well as the results derived from the interviews, reveal a similar phenomenon to that described by Burkert et al. (2011) in the context of a manager. According to the experts, these categories may be necessary for the entire ecosystem and support users who are facing an interaction decision. Therefore, the platform operators focus on customer expertise and use categories that the supplier cannot control. Submission categories that can be affected by the evaluated users seems to be an interesting approach. However, if other uninfluenceable categories are essential for users for their transaction decision and thus for the conversion rates, we recommend including these categories separately and not including them in the overall rating of the user. For example, a separate view could be introduced for user ratings or travel location ratings within a travel platform. Nevertheless, it should be clear to users what should be measured and how the measurement works. Moreover, the operator should be aware of the time users spend on the platform and the capital they invest when doing a transaction.

Using various measures can prevent dysfunctional effects of subjective measurements (Ittner et al. 2003; Prendergast and Topel 1993). Thus, the rare use of multiple measures is quite surprising. It is questionable how many measures a feedback mechanism should include to avoid subjectivity, such as more lenient scores and less differentiation (Moers 2005). However, the trade-off between detailed information and simplicity mentioned by the experts explains the low compliance with this property. We suggest avoiding the use of only an overall or textual evaluation. Operators should pay attention to the trade-off between simplicity and detailed information. In particular, the effects of the feedback mechanism design on feedback provision and conversion rates should be considered.

Another unexpected result is the rare compliance with feedback evaluation. The possibility to evaluate feedback contributes to the reduction of potential dysfunctional effects. Furthermore, subjective performance measurement only operates if trust is high (Simons 1995). However, this operation is not clear concerning feedback mechanisms, as these are intended to reduce the information asymmetries between different market sides and create trust. The low compliance with the feedback evaluation is unexpected, because other researchers such as Klein et al. (2019) 


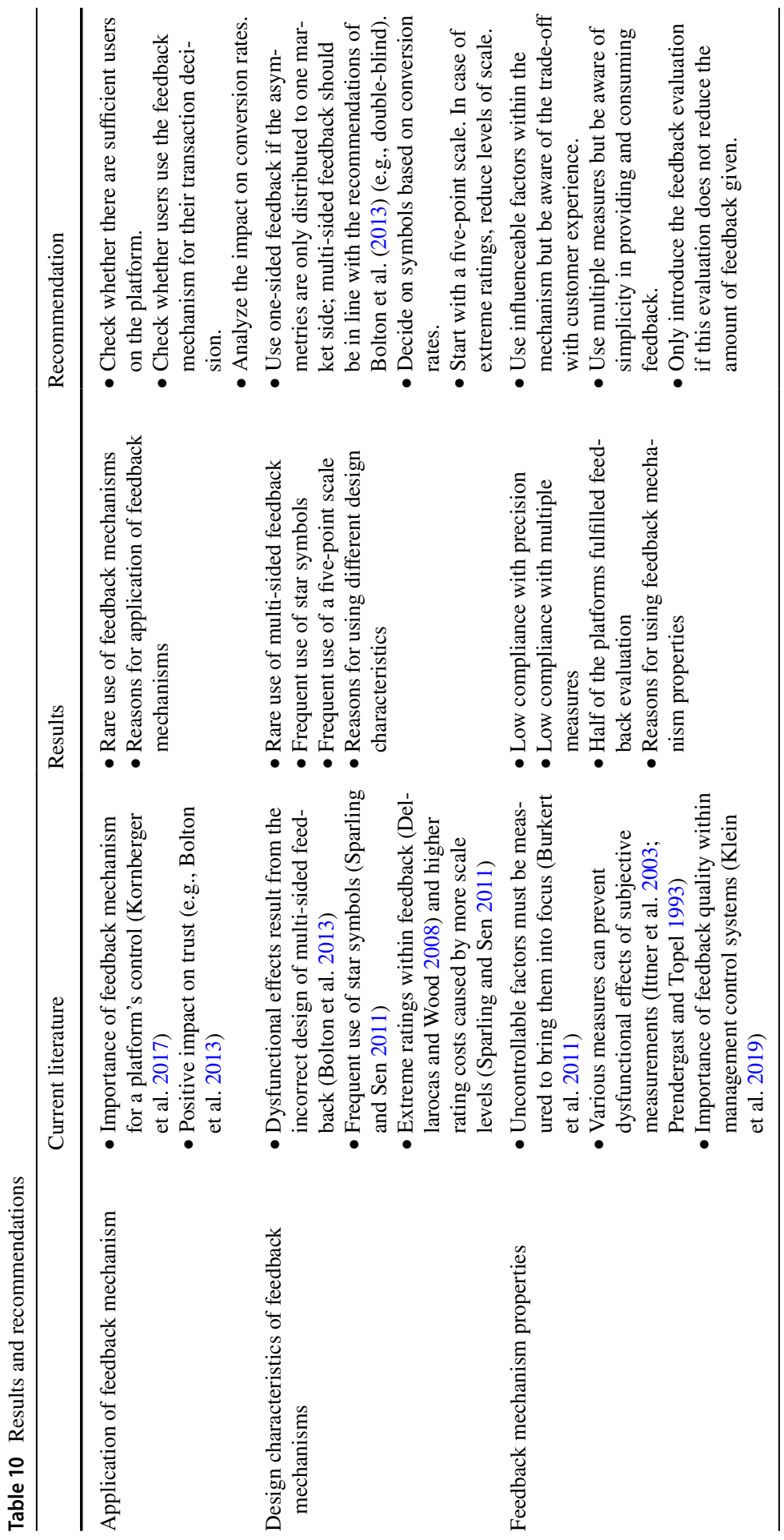


report that feedback evaluation has a significant influence on perceived justice. However, feedback evaluation is related to higher rating costs for the users. Therefore, according to the results of the interviews, the platforms do not use feedback evaluation to set incentives for users to give feedback. We propose that operators should introduce feedback evaluation only if this evaluation does not reduce the amount of feedback given. Additionally, the platforms should ensure that users provide sufficient feedback evaluations and that users use these evaluations to decide on transactions.

Table 10 summarizes our results and the differences from the current literature and provides recommendations for designing feedback mechanisms.

\section{Conclusion}

Our study used a descriptive approach to conceptually outline the field of feedback mechanisms, thereby enabling the understanding and design of this type of control mechanism in research and business practice. Since feedback mechanisms can be interpreted as a specific type of control mechanism refer to the research on control mechanism that is implemented as a means to influence users to implement the platform provider's strategy, we examined the transferability of management control system properties to a platform's feedback mechanism. Therefore, we developed a framework for designing a feedback mechanism based on management control system properties. Subsequently, we examined the use of properties in existing feedback mechanisms. For this purpose, specific feedback mechanisms were analyzed, and the compliance with different management control systems properties was evaluated. The findings suggest that platforms have considered some but not all of the properties of management control systems theory. We also discussed within 14 expert interviews reasons for differences in compliance, which revealed a desire for simplicity and the provision of feedback as primary reasons.

This paper contributes to the literature in the following ways. First, it empirically shows how digital platforms design their mechanisms and provides insights into their decisions. In particular, it gives a morphological box of various criteria. It indicates dominant patterns in nearly all design characteristics (e.g., query method, submission category and scale level). Moreover, the interviews reveals that simplicity and the provision of feedback are essential. Second, our analysis shows to what extent existing feedback mechanisms of digital platforms as decentralized control mechanisms were compliant with the properties of management control systems. More precisely, it shows that sensitivity and verifiability were taken into account by most feedback mechanisms. In contrast, other properties such as precision, multiple measures, and feedback evaluation are not important.

Consequently, this paper contributes to the research field of feedback mechanisms. We show how digital platforms design their feedback mechanisms and provide insight into their decisions. In particular, our paper offers a morphological box of those design characteristics and provides a framework for operators to design, implement, or redesign efficient feedback mechanisms. Furthermore, our analysis shows to what extent existing feedback mechanisms comply with the properties of 
management control systems. Moreover, it reveals reasons for compliance based on expert interviews and highlights trade-offs in designing feedback mechanisms. More specifically, operators should consider interdependencies with other control mechanisms.

Our study is subject to several limitations. First, the selection should preferably be representative, whereas our selection was only based on the most frequently visited websites (e.g., no app-based platforms were part of the analysis). Moreover, business-to-business platforms, such as the Internet-of-Things platforms, were not considered within the analysis. Second, we used single items and did not differentiate within the level of compliance with the properties. Thirdly, the compliance with the properties was analyzed individually, although these properties are used together as a construct. However, this limitation was accepted to demonstrate their compliance, to show feedback mechanism properties and because no correlations were investigated. Fourth, we assumed that platforms implemented feedback mechanisms as a management control system and did not just implement them because they are state-of-the-art.

Funding Open Access funding provided by Projekt DEAL.

Open Access This article is licensed under a Creative Commons Attribution 4.0 International License, which permits use, sharing, adaptation, distribution and reproduction in any medium or format, as long as you give appropriate credit to the original author(s) and the source, provide a link to the Creative Commons licence, and indicate if changes were made. The images or other third party material in this article are included in the article's Creative Commons licence, unless indicated otherwise in a credit line to the material. If material is not included in the article's Creative Commons licence and your intended use is not permitted by statutory regulation or exceeds the permitted use, you will need to obtain permission directly from the copyright holder. To view a copy of this licence, visit http://creativecommons.org/licen ses/by/4.0/.

\section{Appendix A}

See Table 11 
Table 11 Websites excluded within the check (Based on the top 500 Websites in Germany on 25th September 2018)

Exclusion Website (\#)

reason

Duplicates Google.de (2), Ebay-kleinanzeigen.de (8), Google.ru (21), Amazon.com (50), Deref-webd02.de (63), Google.com.ua (73), T.co (77), Telekom.de (108), Ebay.com (115), Google. com.tr (116), Microsoftonline.com (151), Gamepedia.com (182), Fbcdn.net (206), Stackexchange.com (213), Aol.de(218), Googleusercontent.com (227), Ebaystores.de (305), Picclick.de (316), Serienjunkies.org (323), Userapi.com (309), Pinimg.com (414), Amazon.co.uk (437), Twimg.com (453), Cdninstagram.com (473)

Legally Xhamster.com (13), Pornhd.com (20), Livejasmin.com (24), Txxx.com (30), Pornq.com doubtful (35), Xvideos.com (43), Chaturbate.com (45), Youporn.com (56), Upornia.com (62), Hclips.com (68), Bs.to (70), Bongacams.com (76), Xnxx.com (89), Exosrv.com(95), Redtube.com (110), Cloudfront.net (125), Hotmovs.com (132), S.to (136), Cobalten. com (140), Vivo.sx (142), Openload.co (143), Hdzog.com (147), Nextoptim.com (148), Goldesel.to (162), Crptentry.com (167), Share-online.biz (169), Mydirtyhobby. com (171), Workfromhomejobsonline.com (172), Sunmaker.com (179), Joyclub.de (183), Nurxxx.mobi (187), Youporn.sexy (188), Streamkiste.tv (192), Livetv.sx (209), Browsergames2018.com (219), Movie-blog.org (225), Beeg.com (228), Kinox.io (229), Pornpics.com (232), Doublepimpssl.com (248), Exdynsrv.com (252), Gotporn. com (256), Mygully.com (261), Offersuperhub.com (263), Upload.net (267), Vporn. com (271), Pornliebe.com (272), Justporno.sex (279), Jf71qh5v14.com (280), Zononi. com (289), Drtuber.com (291), Ebaydesc.com (294), Ddl-warez.to (298), Mega.nz (308), Tube8.com (311), Hqzjz7fncd.com (322), Lxxx.com (326), Porn300.com (333), Spotscenered.info (334), Kinox.to (339), Hqporner.com (340), Sm.de (346), Kaufmich. com (351), Xhamsterlive.com (352), Boerse.to (354), Turbobit.net (358), Ddl.me (362), Tnaflix.com (363), Analdin.com (365), Streamcloud.eu (369), Hd-streams.org (382), Ladies.de (385), Cam4.de.com (386), Dref.pw (398), Fremdgehen.69.com (399), 4tube. com (401), Porn.com (412), Imagefap.com (425), Movie4k.io (427), Runtnc.net (428), Canna.to (432), Tubepornclassic.com (433), Medium.com (434), Predictiondisplay.com (424), Dnckawxatc.com (454), Spankwire.com (457), Eroprofile.com (459), Nuvid.com (462), Motherless.com (469), Xtube.com (476), Planetromeo.com (480), Jizzbunker.com (486), Pornhub.com (494), Poppen.de (498), Lwank.tv (499)

Language Seasonvar.ru (128), Ria.ru (154), Aparat.com (156), Gidonline.in (178), Germany.ru (181), Rutracker.org (193), Kinopoisk.ru (204), 1tv.ru (208), Yaplakal.com (211), Echo.msk.ru (212), Ensonhaber.com (217), Kinogo.by (242), Olx.ua (257), Vesti.ru (268), Lentainform.com (270), Gazeta.ru (278), Rutube.ru (290), Kinokrad.co (293), Kp.ru (300), Rbc.ru (307), Pikabu.ru (318), Fishki.net (312), Gazetaexpress.com (364), Sportmail.ru (368), Baidu.com (370), 4pada.ru (376), 24smi.ifo (377), Yadi.sk (381), Filmix.co (389), Ontvtime.ru (396), Rutor.info (440), Mirtesen.ru (446), Hdrezka.ag (449), Newsru. com (460), Avito.ru (467), Smi2.ru (470), Mk.ru (482), Vz.ru (483), Drive2.ru (491), Liveinternet.ru (492)

No access Vk.com (9), Blogspot.de (37), Patreon.com (391), Nexusmods.com (474) 
Table 11 (continued)

Exclusion Website (\#)

reason

No platform Mail.ru (10), Web.de (15), Yahoo.com (17), Gmx.net (19), T-online.de (22), Spiegel.de (23), Bild.de (26), Live.com (27), Netflix.com (31), Chip.de (32), Otto.de (33), Focus. de (36), Wetter.com (39), Welt.de (40), Bahn.de (48), Microsoft.com (49), Msn.com (52), Dhl.de (53), Presseportal.de (55), Zdf.de (57), Wordpress.com (58), 1und1.de (59), Heise.de (61), Wetteronline.de (64), Tagesschau.de (66), Zeit.de (67), Telekom.com (69), Deutsche-bank.de (71), Shop-apotheke.com (71), Imdb.com (74), Vodafone.de (75), Apple.com (78), Commerzbank.de (81), Kicker.de (82), Mediamarkt.de (83), Computerbild.de (85), Wetter.de (88), Ing-diba.de (90), N-tv.de (91), Sueddeutsche.de (92), Adobe. com (94), Lidl.de (97), Faz.net (98), Vice.com (99), Dkb.de (100), Rt.com (101), Ikea. com (102), Dict.cc (103), Freenet.de (105), Zalando.de (109), Mozilla.org (111), Convert2mp3.net (113), Leo.org (114), Duden.de (117), Filecrypt.cc (118), Aol.com (120), Fritz.box (121), Comdirekt.de (123), Steampowered.com (124), Office.com (126), Strato. de (127), Arbeitsargentur.de (129), Sunnyplayer.com (130), Giga.de (131), Ardmediathek.de (134), Saturn.de (135), Spotify.com (137), Outbrain.com(144), Sky.de (146), Meinestadt.de (149), Lenta.ru (150), Sputniknews.com (152), Transfermarkt.de (155), Battle.net (157), Deutschepost.de (158), Pons.com (161), Tagesspiegel.de (163), Oath. com (164), Bonprix.de (166), Linguee.de (166), Bbc.com (170), Epochtimes.de (173), Dw.com (174), Tvnow.de (175), Exoclick.com (176), Wikimedia.org (177), Hm.com (180), Real.de (185), Wdr.de (186), O2online.de (191), Pi-news.net (194), Steamcommunity.com (199), Ndr.de (200), Shein.com (201), Sofort.com (202), Daserste.de (203), Stern.de (210), Tvspielfilm.de (214), Bet365.com (215), Berliner-sparkasse.de (221), Computerbase.de (222), Ard.de (224), Finanzen.net (226), Hornbach.de (230), Pcwelt. de (231), Wowhead.com (233), Obi.de (234), Notebooksbilliger.de(235), Berlin.de (236), Journalistenwatch.com (238), Merkur.de (240), Fernsehserien.de (241), Myhermes.de (244), Sport1.de (245), Express.de (246), Dastelefonbuch.de (247), Thomann.de (249), Br.de (253), Netzwelt.de (255), Tchibo.de (258), Siteadvisor.com (259), Samsung. com (260), Gamestar.de (264), Factaholics.com (265), Tipico.de (266), Arte.tv (269), Doublepimp.com (273), Mdr.de (274), Moviepilot.de (275), Playstation.com (276), Dailyholics.com (281), Rp-online.de (283), Jimdo.com(284), Targobank.de (287), Hartgeld. com (288), Adac.de (292), Reverso.net (295), Webmasterplan.com (296), Filmstarts.de (297), Zippyshare.com (299), Kino.de (301), Sportschau.de (302), Dasoertliche.de (303), Testbericht.de (304), Bauhaus.info (306), Rtl.de (310), Theguardian.com (312), Amazonaws.com (313), Ryanair.com (314), Tz.de (315), Flixbus.de (317), Forgeofempires. com (319), Alternate.de (324), Unitymedia.de (325), Elster.de (327), Aldi-sued.de (330), Consorsbank.de (331), Baur.de (335), Imagetwist.com (336), Zukxd6fkxqn.com (337), Handelsblatt.com (341), Bayern.de (345), Humblebundle.com (348), Huffingtonpost.de (350), Savefrom.net (355), Wargaming.net (356), Dm.de (357), Pearl.de (359), Avm.de (360), Popads.net (361), Cnet.com (366), Rewe.de (367), Opodo.de (371), Asos.de (372), Lufthansa.com (373), Postbank.de (375), Woxikon.de (378), Wunderino.com (379), Norisbank.de (380), Songtexte.com (383), Golem.de (384), Haspa.de (387), Gamespot. com (388), Thalia.de (394), Op.gg (395), Nrw.de (397), Fußball.de (402), Apothekenumschau.de (404), Imagebam.com (405), Speedtest.net (406), Oload.download (407), Doubleclick.net (408), Mindfactory.de (409), Mopo.de (410), Spinger.com (411), Arcor. de (413), Mpnrs.com (420), Nih.gov (421), Deepl.com (422), Swr.de (423), Derwesten. de (424), Elvenar.com (426), Sportbible.com (429), Intellitest.me (430), Autobild.de (431), Lapalingo.com (435), Arabdict.com (436), Junbi-tracker-com (438), Ccleaner. com (443), Softonic.com (444), Mytyos.de (445), Hp.com (447), Schulferien.org (448), Lbb.de (450), Dazn.com (452), Serienjunkies.de (455), Lotto.de (458), Coinmarketcap. com (461), Bunte.de (463), Manofile.com (464), Tag24.de (466), Epicgames.com (468), Clever-tanken.de (471), Bet-at-home.com (472), Aldi-nord.de (275), Bbc.co.uk (478), Yumpu.com (481), Galeria-kaufhof.de(485), Taz.de (489), Ladbible.com (490), Rapidgator.net (493), Pc-magazine.de (495), Platincasino.com (497), Eurowings.com 


\section{Appendix B}

\section{See Table 12}

Table 12 Websites classified as platforms, having a feedback mechanism (Based on the top 500 Websites in Germany on 25th September 2018)

\begin{tabular}{ll}
\hline Platform type & Website (\#, country) \\
\hline Marketplace & Amazon.de (4, US), Ebay.de (6, US), Mobile.de (38, DE), Immobilienscout24.de (41, \\
& DE), Aliexpress.com (42, CN), Autoscout24.de (86, DE), Discogs.com (190, US), \\
& Etsy.com (205, US), Gearbest.com (220, CN), Conrad.de (243, DE), Wish.com (250, \\
& US), Eventim.de (285, DE), Kleiderkreisel.de (320, DE), Groupon.de (342, US), \\
& Alibaba.com (416, CN), Lieferando.de (419, NLD), Rakuten.de (459, JP) \\
Rating & Idealo.de (47, DE), Check24.de (79, DE), Holidaycheck.de (153, CH), Tripadvisor. \\
& de (159, US), Markt.de (184, DE), Indeed.com (195, US), Jameda.de (329, DE), \\
& Geizhals.de (344, AT), Trustpilot.com (393, DK) \\
Social media & Youtube.com (3, US), Facebook.de (5, US), Instagram.com (11, US), Ok.ru (14, RUS), \\
& Twitter.com (18, US), Reddit.com (25, US), Tumblr.com (44, US), Imgur.com (84, \\
& US), Linkedin.com (87, US), Xing.com (93, DE), Chefkoch.de (96, DE), Stackover- \\
& flow.com (106, US), Livejournal.com (112, US), Mydealz.de (119, DE), Soundcloud. \\
& com (122, DE), Vimeo.com (133, US), 9gag.com (138, HKG), Deviantart.com (160, \\
& US), Pixabay.com (223, DE), Quora.com (239, US), Flickr.com (251, US), Roblox. \\
& com (277, US), Genius.com (282, US), Archive.org (338, US), Jappy.com (392, DE), \\
& Pinterest.de (400, US), Sourceforge.net (418, US), Gfycat.com (465, US) \\
& Booking.com (46, NLD), Airbnb.de (US), Ab-in-den-urlaub.de (374, DE), Expedia.de \\
& (417, US)
\end{tabular}

\section{Appendix C}

\section{See Table 13}




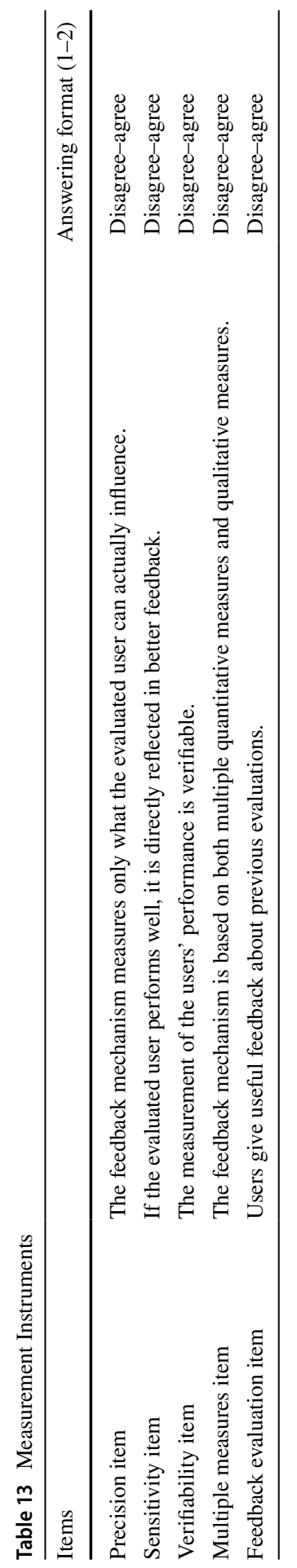




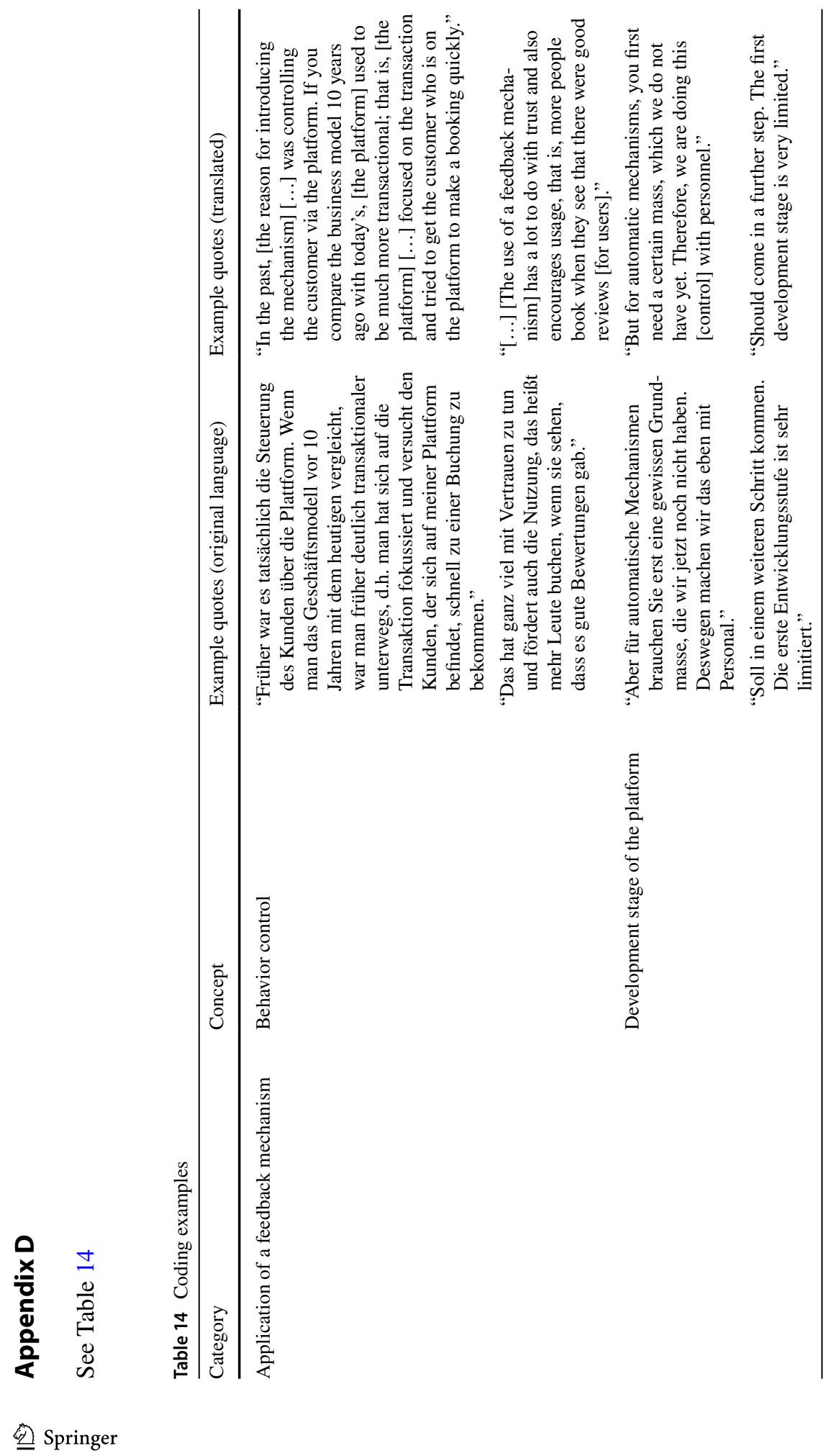




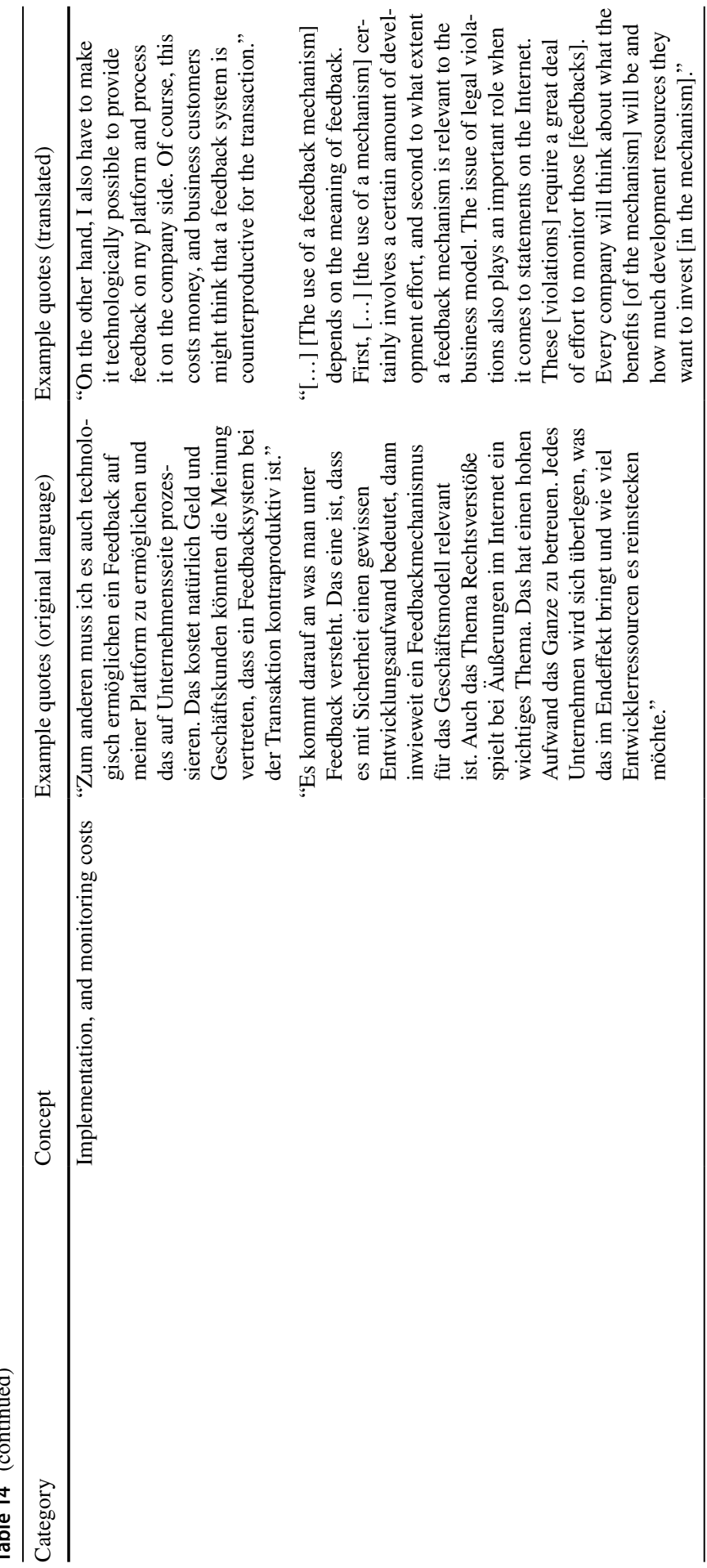




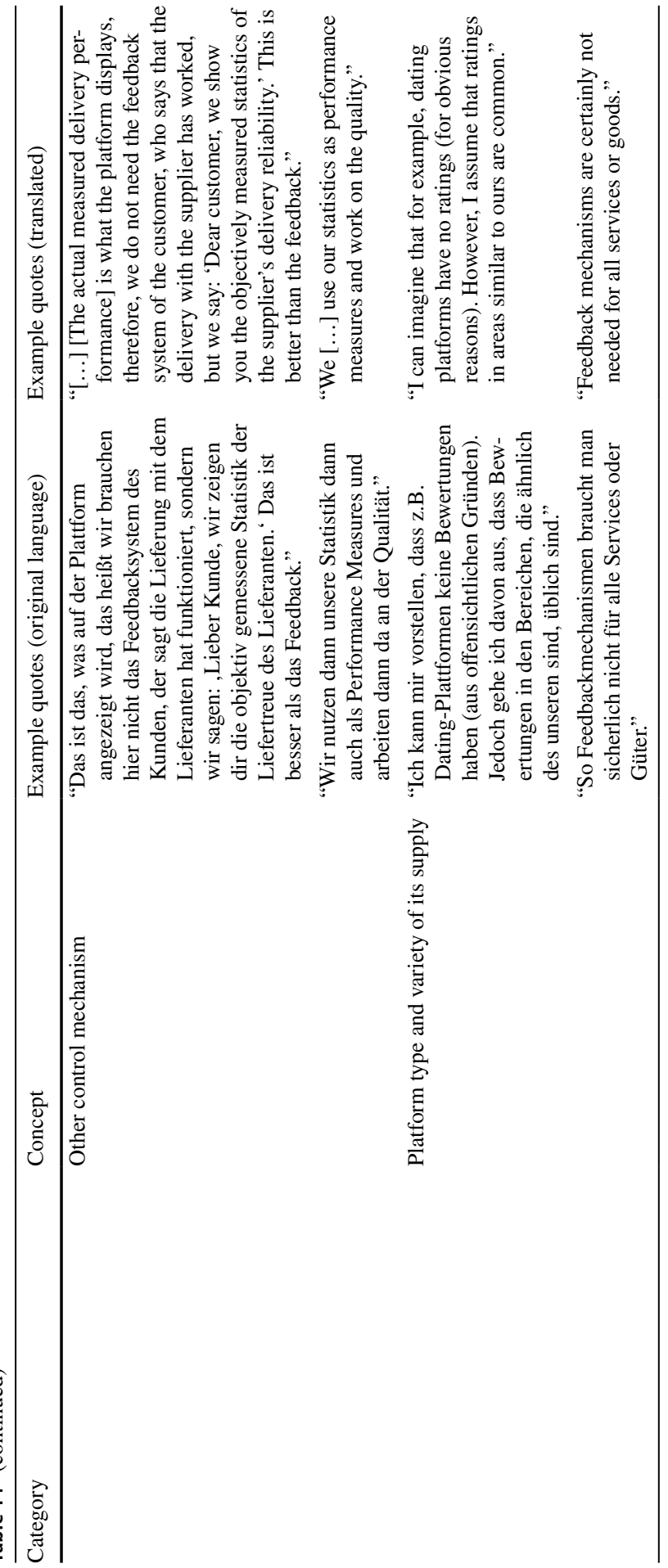




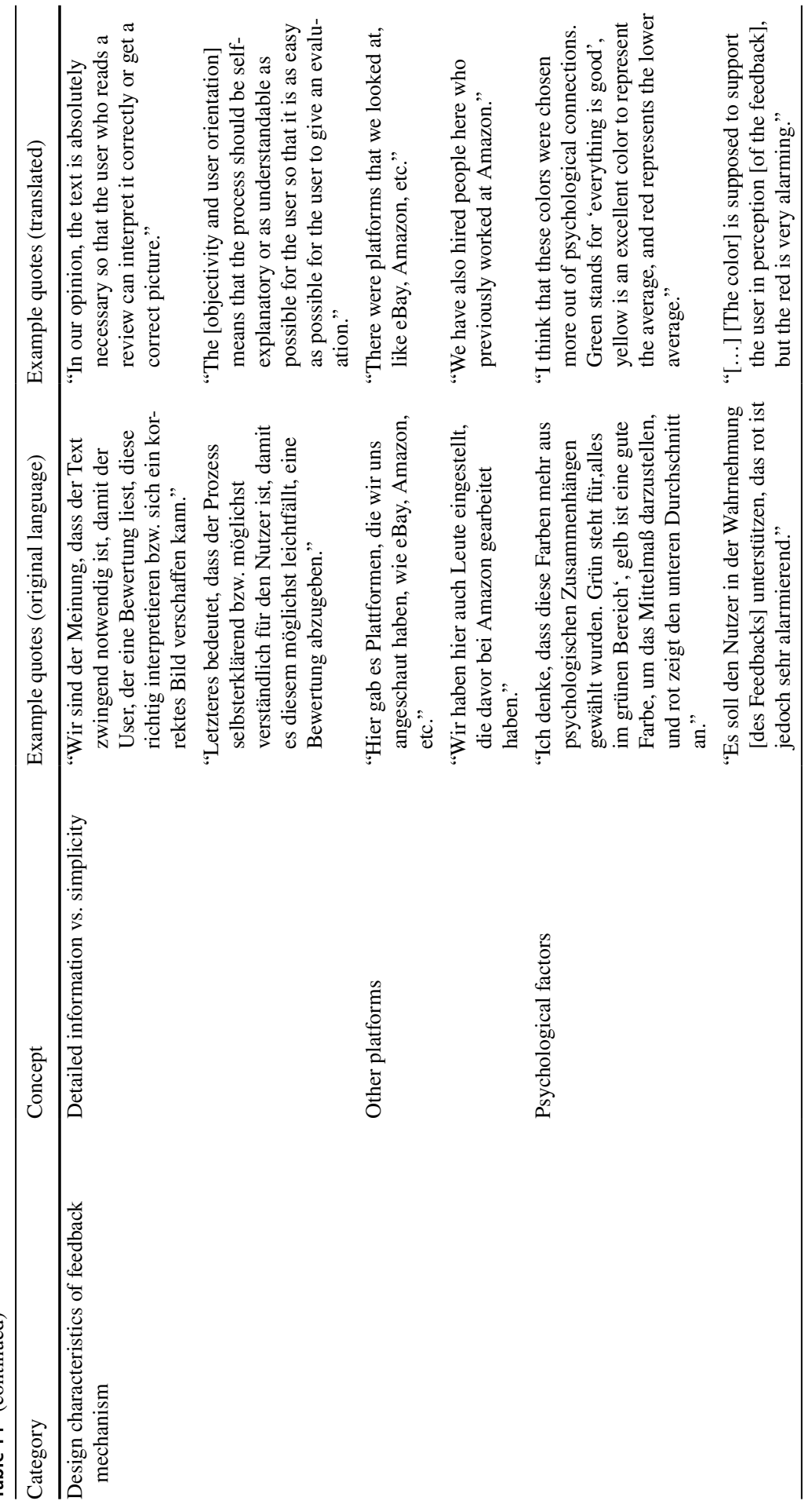




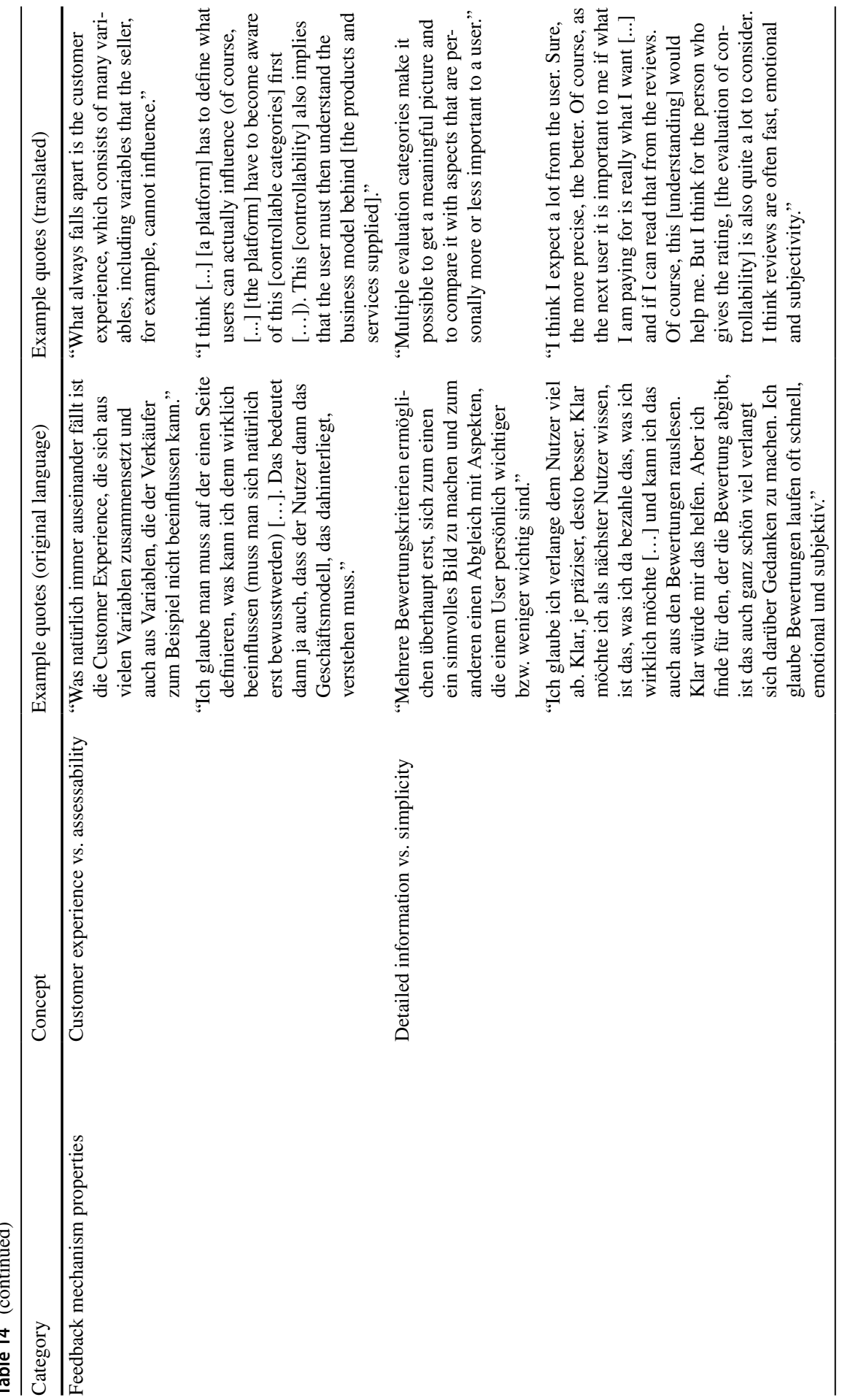




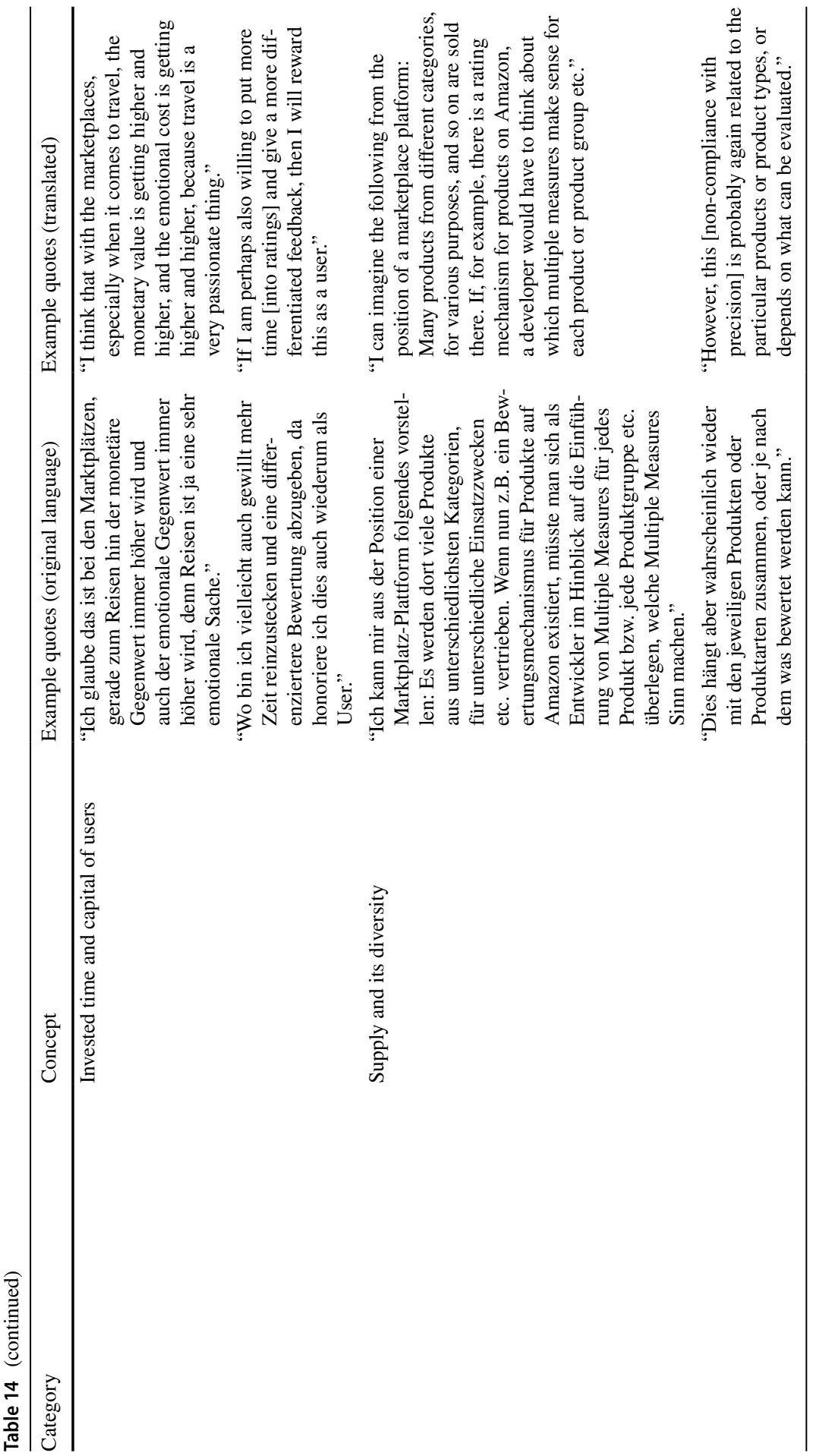




\section{References}

Abramova O, Veltri N, Krasnova H, Kiatprasert S, Buxmann P (2016) Physician-rating platforms: how does your doctor feel? 22nd Americas Conference on Information Systems. pp 1-10

Alexa (2018) About us. https://www.alexa.com/about. Accessed 25 Sep 2018

Alexander S, Ruderman M (1987) The role of procedural and distributive justice in organizational behavior. Soc Just Res 1(2):177-198. https://doi.org/10.1007/BF01048015

Anthony RN, Govindarajan V, Hartmann FGH, Krause K, Nilsson G (2014) Management control systems, 1st Europ edn. McGrawHill Education Higher Education, London

Armstrong M (2006) Competition in two-sided markets. RAND J Econ 37(2):668-691. https://doi. org/10.1111/j.1756-2171.2006.tb00037.x

Ba S, Pavlou PA (2002) Evidence of the effect of trust building technology in electronic markets: price premiums and buyer behavior. Manag Inf Syst Q 26(3):243-268

Bajari P, Hortaçsu A (2003) The winner's curse, reserve prices, and endogenous entry: empirical insights from eBay auctions. RAND J Econ 34:329. https://doi.org/10.2307/1593721

Banker RD, Datar SM (1989) Sensitivity, precision, and linear aggregation of signals for performance evaluation. J Account Res 27(1):21-39. https://doi.org/10.2307/2491205

Becker J, Herwig S, Pöppelbus J, Tiebe D, Winkelmann A (2009) Funktionale Gestaltungsoptionen von Online-Bewertungssystemen. In: Proceedings of GI Jahrestagung:2098-2112

Berger R, Schmitt K (2005) Vertrauen bei Internetauktionen und die Rolle von Reputation, Informationen, Treuhandangebot und Preisniveau. Kölner Zeitschrift für Soziologie und Sozialpsychologie 57(1):86-111. https://doi.org/10.1007/s11577-005-0112-X

Bharadwaj KK, Al-Shamri MYH (2009) Fuzzy computational models for trust and reputation systems. Electron Commer Res Appl 8(1):37-47. https://doi.org/10.1016/j.elerap.2008.08.001

Bisbe J, Batista-Foguet J-M, Chenhall R (2007) Defining management accounting constructs: a methodological note on the risks of conceptual misspecification. Account Organ Soc 32(7-8):789-820. https://doi.org/10.1016/j.aos.2006.09.010

Bolton GE, Katok E, Ockenfels A (2004) How effective are electronic reputation mechanisms? An experimental investigation. Manag Sci 50(11):1587-1602. https://doi.org/10.1287/mnsc.1030.0199

Bolton G, Greiner B, Ockenfels A (2013) Engineering trust: reciprocity in the production of reputation information. Manag Sci 59(2):265-285. https://doi.org/10.1287/mnsc.1120.1609

Bolton G, Greiner B, Ockenfels A (2018) Dispute resolution or escalation? The strategic gaming of feedback withdrawal options in online markets. Manag Sci 64(9):4009-4031. https://doi.org/10.1287/ mnsc.2017.2802

Bommer WH, Johnson JL, Rich GA, Podsakoff PM (1995) On the interchangeability of objective and subjective measures of employee performance: a meta-analysis. Pers Psychology 48(3):587-605. https://doi.org/10.1111/j.1744-6570.1995.tb01772.x

Boudreau K (2010) Open platform strategies and innovation: granting access vs. devolving control. Manag Sci 56(10):1849-1872. https://doi.org/10.1287/mnsc.1100.1215

Brousseau E, Penard T (2007) The economics of digital business models: a framework for analyzing the economics of platforms. Rev Netw Econ 6(2):746. https://doi.org/10.2202/1446-9022.1112

Brownell P (1982) The role of accounting data in performance evaluation, budgetary participation, and organizational effectiveness. J Account Res 20(1):12. https://doi.org/10.2307/2490760

Burkert M, Fischer FM, Schäffer U (2011) Application of the controllability principle and managerial performance: the role of role perceptions. Manag Account Res 22(3):143-159. https://doi. org/10.1016/j.mar.2011.03.002

Burney LL, Henle CA, Widener SK (2009) A path model examining the relations among strategic performance measurement system characteristics, organizational justice, and extra- and in-role performance. Account Organ Soc 34(3-4):305-321. https://doi.org/10.1016/j.aos.2008.11.002

Butler SA, Ghosh D (2015) Individual differences in managerial accounting judgments and decision making. Br Account Rev 47(1):33-45. https://doi.org/10.1016/j.bar.2014.09.002

Cabral L, Hortaçsu A (2010) The dynamics of seller reputation: evidence from eBay. J Ind Econ 58(1):54-78. https://doi.org/10.1111/j.1467-6451.2010.00405.x

Chen L, Jiang T, Li W, Geng S, Hussain S (2017) Who should pay for online reviews? Design of an online user feedback mechanism. Electron Commer Res Appl 23:38-44. https://doi.org/10.1016/j. elerap.2017.04.005 
Chenhall RH (2003) Management control systems design within its organizational context: findings from contingency-based research and directions for the future. Account Organ Soc 28(2-3):127-168. https://doi.org/10.1016/S0361-3682(01)00027-7

Chevalier JA, Mayzlin D (2006) The effect of word of mouth on sales: online book reviews. J Market Res 43(3):345-354. https://doi.org/10.1509/jmkr.43.3.345

Chua AYK, Banerjee S (2015) Understanding review helpfulness as a function of reviewer reputation, review rating, and review depth. J Assoc Inf Sci Tech 66(2):354-362

Corbin JM, Strauss A (1990) Grounded theory research: procedures, canons, and evaluative criteria. Qual Sociol 13(1):3-21. https://doi.org/10.1007/BF00988593

DeFond ML, Park CW (1997) Smoothing income in anticipation of future earnings. J Account Econ 23(2):115-139. https://doi.org/10.1016/S0165-4101(97)00004-9

Dellarocas C (2003) The digitization of word of mouth: promise and challenges of online feedback mechanisms. Manag Sci 49(10):1407-1424. https://doi.org/10.1287/mnsc.49.10.1407.17308

Dellarocas C (2004) Building trust online. In: Doukidis GI, Mylonopoulos N, Pouloudi N (eds) Social and economic transformation in the digital era. Idea Group, Hershey PA, pp 95-113

Dellarocas C, Wood CA (2008) The sound of silence in online feedback: estimating trading risks in the presence of reporting bias. Manag Sci 54(3):460-476. https://doi.org/10.1287/mnsc.1070.0747

Dent JF (1987) Tensions in the design of formal control systems: a field study in a computer company. In: Bruns WJ, Kaplan RS (eds) Accounting and management: field study perspectives. Harvard Business School Press, Boston, pp 119-145

Dorfer L (2016) Datenzentrische Geschäftsmodelle als neuer Geschäftsmodelltypus in der ElectronicBusiness-Forschung: Konzeptionelle Bezugspunkte, Klassifikation und Geschäftsmodellarchitektur. Schmalenbachs Z betriebswirtsch Forsch 68(3):307-369. https://doi.org/10.1007/s4147 1-016-0014-9

Dunk AS (1993) The effect of budget emphasis and information asymmetry on the relation between budgetary participation and slack. Account Rev 68(2):400-410

Einav L, Farronato C, Jonathan Leviny J (2015) Peer-to-peer markets. SIEPR 15-029:1-32

Eisenhardt K (1989) Building theories from case study research. Acad Manag Rev 14(4):532-550

Evans DS, Schmalensee R (2016) Matchmakers: the new economics of multisided platforms. Harvard Business Review Press, Boston, Massachusetts

Fazzolari M, Cozza V, Petrocchi M, Spognardi A (2017) A study on text-score disagreement in online reviews. Cogn Comput 9(5):689-701. https://doi.org/10.1007/s12559-017-9496-y

Ferreira A, Otley D (2009) The design and use of performance management systems: an extended framework for analysis. Manag Account Res 20(4):263-282. https://doi.org/10.1016/j.mar.2009.07.003

Folger R, Konovsky MA (1989) Effects of procedural and distributive justice on reactions to pay raise decisions. Acad Manag J 32(1):115-130. https://doi.org/10.2307/256422

Ghosh D (2005) Alternative measures of managers' performance, controllability, and the outcome effect. Behav Res Account 17(1):55-70. https://doi.org/10.2308/bria.2005.17.1.55

Giraud F, Langevin P, Mendoza C (2008) Justice as a rationale for the controllability principle: a study of managers' opinions. Manag Account Res 19(1):32-44. https://doi.org/10.1016/j.mar.2007.09.002

Globerson S (1985) Issues in developing a performance criteria system for an organization. Int J Prod Res 23(4):639

Grabner I, Moers F (2013) Management control as a system or a package? Conceptual and empirical issues. Account Organ Soc 38(6-7):407-419. https://doi.org/10.1016/j.aos.2013.09.002

Groen BAC, Wouters MJF, Wilderom CPM (2017) Employee participation, performance metrics, and job performance: a survey study based on self-determination theory. Manag Account Res 36:51-66. https://doi.org/10.1016/j.mar.2016.10.001

Gutt D, Neumann J, Zimmermann S, Kundisch D, Chen J (2019) Design of review systems: a strategic instrument to shape online reviewing behavior and economic outcomes. J Strat Inf Syst 28(2):104117. https://doi.org/10.1016/j.jsis.2019.01.004

Hagiu A (2009) Two-sided platforms: product variety and pricing structures. J Econ Manag Strat 18(4):1011-1043. https://doi.org/10.1111/j.1530-9134.2009.00236.x

Hartmann F, Slapničar S (2009) How formal performance evaluation affects trust between superior and subordinate managers. Account Organ Soc 34(6-7):722-737. https://doi.org/10.1016/j. aos.2008.11.004

Henemann RL (1986) The relationship between supervisory ratings and results-oriented measures of performance: a meta-analysis. Pers Psychology 39(4):811-826. https://doi. org/10.1111/j.1744-6570.1986.tb00596.x 
Henemann RL, Moore ML, Wexley KN (1987) Performance-rating accuracy: a critical review. J Bus Res 15(5):431-448. https://doi.org/10.1016/0148-2963(87)90011-7

Hoffman K, Zage D, Nita-Rotaru C (2009) A survey of attack and defense techniques for reputation systems. ACM Comput Surv 42(1):1-31. https://doi.org/10.1145/1592451.1592452

Holmström B (1979) Moral hazard and observability. Bell J Econ 10(1):74. https://doi.org/10.2307/30033 20

Huffman C, Cain LB (2000) Effects of considering uncontrollable factors in sales force performance evaluation. Psychol Mark 17(9):799-833. https://doi.org/10.1002/1520-6793(20000 9) 17:9<799:AID-MAR4>3.0.CO;2-D

Hu N, Pavlou PA, Zhang J (2017) On self-selection biases in online product reviews. Manag Inf Syst Q 41(2):449-471https://doi.org/10.25300/MISQ/2017/41.2.06

Hui X, Saeedi M, Sundaresan N (2019) Adverse selection or moral hazard: an empirical study. J Ind Econ 66(3):610-649. https://doi.org/10.1111/joie.12183

Ilgen DR, Fisher CD, Taylor MS (1979) Consequences of individual feedback on behavior in organizations. J Appl Psychol 64(4):349-371. https://doi.org/10.1037/0021-9010.64.4.349

Ittner CD, Larcker DF, Meyer MW (2003) Subjectivity and the weighting of performance measures: evidence from a balanced scorecard. Account Rev 78(3):725-758. https://doi.org/10.2308/ accr.2003.78.3.725

Jiang Y, Guo H (2015) Design of consumer review systems and product pricing. Inf Syst Res 26(4):714730. https://doi.org/10.1287/isre.2015.0594

Jøsang A, Ismail R, Boyd C (2007) A survey of trust and reputation systems for online service provision. Decis Support Syst 43(2):618-644. https://doi.org/10.1016/j.dss.2005.05.019

Kaplan RS, Norton DP (1996) The balanced scorecard: translating strategy into action, 1st edn. Harvard Business School Press, Boston, Mass

Kerr S (1975) On the folly of rewarding A, while hoping for B. Acad Manag J 18(4):769-783. https://doi. org/10.2307/255378

Klein L, Beuren IM, Dal Vesco D (2019) Effects of the management control system in unethical behaviors. RAUSP Manag J 54(1):54-76. https://doi.org/10.1108/RAUSP-06-2018-0036

Knee JA (2018) Why some platforms are better than others? MIT SLOAN Manag Rev 59(2):18-20

Kornberger M, Pflueger D, Mouritsen J (2017) Evaluative infrastructures: accounting for platform organization. Account Organ Soc 60:79-95. https://doi.org/10.1016/j.aos.2017.05.002

Langevin P, Mendoza C (2013) How can management control system fairness reduce managers' unethical behaviours? Euro Manag J 31(3):209-222. https://doi.org/10.1016/j.emj.2012.12.001

Langfield-Smith K (1997) Management control systems and strategy: a critical review. Account Organ Soc 22(2):207-232. https://doi.org/10.1016/S0361-3682(95)00040-2

Lee S-G, Trimi S, Yang C-G (2018) Perceived usefulness factors of online reviews: a study of Amazon. com. J Comput Inf Syst 58(2):344-352. https://doi.org/10.1080/08874417.2016.1275954

Li X, Hitt LM (2008) Self-selection and information role of online product reviews. Inf Syst Res 19(4):456-474. https://doi.org/10.1287/isre.1070.0154

Libby T (2003) The effect of fairness in contracting on the creation of budgetary slack. In: Advances in accounting behavioral research. Emerald Group Publishing Limited, pp. 145-169

Lindquist TM (1995) Fairness as an antecedent to participative budgeting: examining the effects of distributive justice, procedural justice and referent cognitions on satisfaction and performance. $\mathrm{J}$ Manag Account Res 7:122-147

Little HT, Magner NR, Welker RB (2002) The fairness of formal budgetary procedures and their enactment. Group Organ Manag 27(2):209-225. https://doi.org/10.1177/10501102027002003

Liu Z, Park S (2015) What makes a useful online review? Implication for travel product websites. Tour Manag 47(2):140-151. https://doi.org/10.1016/j.tourman.2014.09.020

Magner NR, Johnson GG, Little HT, Blair Staley A, Welker RB (2006) The case for fair budgetary procedures. Manag Audit J 21(4):408-419. https://doi.org/10.1108/02686900610661414

Mayzlin D, Dover Y, Chevalier JA (2014) Promotional reviews: an empirical investigation of online review manipulation. Am Econ Rev 104(8):2421-2455

McDonald CG, Slawson VC (2002) Reputation in an internet auction market. Econ Inq 40(4):633-650. https://doi.org/10.1093/ei/40.4.633

McNally GM (1980) Responsibility accounting and organisational control: some perspectives and prospects. J Bus Finance Account 7(2):165-181. https://doi.org/10.1111/j.1468-5957.1980.tb00735.x

Melnik MI, Alm J (2002) Does a seller's ecommerce reputation matter? Evidence from eBay auctions. J Ind Econ 50(3):337-349. https://doi.org/10.1111/1467-6451.00180 
Merchant KA (1985) Budgeting and the propensity to create budgetary slack. Account Organ Soc 10(2):201-210. https://doi.org/10.1016/0361-3682(85)90016-9

Merchant KA (1990) The effects of financial controls on data manipulation and management myopia. Account Organ Soc 15(4):297-313. https://doi.org/10.1016/0361-3682(90)90021-L

Merchant KA (2006) Measuring general managers' performances: market, accounting and combinationof-measures systems. Account Audit Account J 19(6):893-917. https://doi.org/10.1108/09513 570610709917

Merchant KA, Rockness J (1994) The ethics of managing earnings: an empirical investigation. J Account Public Policy 13(1):79-94. https://doi.org/10.1016/0278-4254(94)90013-2

Merchant KA, van der Stede WA (2017) Management control systems: performance measurement, evaluation and incentives, 4th edn. Pearson, Harlow

Milani K (1975) The relationship of participation in budget-setting to industrial supervisor performance and attitudes: a field study. Account Rev 50(2):274-284

Moers F (2005) Discretion and bias in performance evaluation: the impact of diversity and subjectivity. Account Organ Soc 30(1):67-80. https://doi.org/10.1016/j.aos.2003.11.001

Moers F (2006) Performance measure properties and delegation. Account Rev 81(4):897-924. https://doi. org/10.2308/accr.2006.81.4.897

Mudambi S, Schuff D (2010) What makes a helpful online review? A study of customer reviews on Amazon.com. Manag Inf Syst Q 34(1):185-200

Mudambi SM, Schuff D, Zhang Z (2014) Why aren't the stars aligned? An analysis of online review content and star ratings. In: 47th Hawaii international conference on system sciences. https://doi. org/10.1109/HICSS.2014.389

Neely A, Richards H, Mills J, Platts K, Bourne M (1997) Designing performance measures: a structured approach. Int J Oper Prod Manag 17(11):1131-1152. https://doi.org/10.1108/01443579710177888

Nosko C, Tadelis S (2015) The limits of reputation in platform markets: an empirical analysis and field experiment. Working Paper 20830, National Bureau of Economic Research

Otley D (1999) Performance management: a framework for management control systems research. Manag Account Res 10(4):363-382. https://doi.org/10.1006/mare.1999.0115

Panagopoulos A, Koutrouli E, Tsalgatidou A (2017) Modeling and evaluating a robust feedbackbased reputation system for e-commerce platforms. ACM Trans Web 11(3):1-55. https://doi. org/10.1145/3057265

Parker G, van Alstyne M, Choudary SP (2016) Platform revolution: how networked markets are transforming the economy and how to make them work for you, 1st edn. W.W. Norton \& Company, New York, London

Prendergast C, Topel R (1993) Discretion and bias in performance evaluation. Eur Econ Rev 37(2):355365. https://doi.org/10.1016/0014-2921(93)90024-5

Prendergast C, Topel RH (1996) Favoritism in organizations. J Political Econ 104(5):958-978. https:// doi.org/10.1086/262048

Resnick P, Zeckhauser R (2002) Trust among strangers in internet transactions: empirical analysis of eBay's reputation system. In: Baye MR (ed) The economics of the internet and E-commerce. Elsevier Science, Amsterdam, Boston, pp 127-157

Resnick P, Zeckhauser R, Swanson J, Lockwood K (2006) The value of reputation on eBay: a controlled experiment. Exp Econ 9:79-101. https://doi.org/10.1007/s10683-006-4309-2

Roberson QM, Stewart MM (2006) Understanding the motivational effects of procedural and informational justice in feedback processes. Br J Psychol 97(3):281-298. https://doi.org/10.1348/00071 $2605 \times 80146$

Rochet J-C, Tirole J (2003) Platform competition in two-sided markets. J Eur Econ Assoc 1(4):990-1029

Sänger J, Pernul G (2018) Interactive reputation systems. Bus Inf Syst Eng 60(4):273-287. https://doi. org/10.1007/s12599-017-0493-1

Schindler RM, Bickart B (2012) Perceived helpfulness of online consumer reviews: the role of message content and style. J Consum Behav 11(3):234-243. https://doi.org/10.1002/cb.1372

Simons R (1995) Levers of control: how managers use innovative control systems to drive strategic renewal. Harvard Business School Press, Boston, Mass

Sparling EI, Sen S (2011) Rating: how difficult is it? In: Mobasher B (ed) Proceedings of the fifth ACM conference on Recommender systems. ACM, New York, NY, p 149

Steur AJ, Bayrle N (2020) S-curves in platform-based business: facing the challenge of the tipping point. In: Proceedings of the 24th Pacific Asia conference on information systems (PACIS), pp 1-14 
Tadelis S (2016) Reputation and feedback systems in online platform markets. Annu Rev Econ 8(1):321340. https://doi.org/10.1146/annurev-economics-080315-015325

Tiwana A (2014) Platform ecosystems: aligning architecture, governance, and strategy. Morgan Kaufmann, Waltham, MA

van Alstyne M, Parker G, Choudary SP (2016) Pipelines, platforms, and the new rules of strategy: scale now trumps differentiation. Harv Bus Rev 94(4):54-62

Widener SK (2006) Human capital, pay structure, and the use of performance measures in bonus compensation. Manag Account Res 17(2):198-221. https://doi.org/10.1016/j.mar.2005.06.001

Yin RK (2009) Case study research: design and methods, 4th edn. Sage, Thousand Oaks, CA

Zervas G, Proserpio D, Byers J (2015) A first look at online reputation on Airbnb, where every stay is above average. SSRN J. https://doi.org/10.2139/ssrn.2554500

Zhang K, Sarvary M (2015) Differentiation with user-generated content. Manag Sci 61(4):898-914. https ://doi.org/10.1287/mnsc.2014.1907

Zhang R, Gao M, He X, Zhou A (2016) Learning user credibility for product ranking. Knowl Inf Syst 46(3):679-705. https://doi.org/10.1007/s10115-015-0880-1

Publisher's Note Springer Nature remains neutral with regard to jurisdictional claims in published maps and institutional affiliations. 